Lexis Vol. XLV (1) 2021: 77-123

\title{
América en el Diccionario de la lengua castellana de la Real Academia Española (1817-1852)*
}

\author{
Gloria Clavería Nadal \\ https://orcid.org/0000-0001-8294-8652 \\ Universidad Autónoma de Barcelona \\ gloria.claveria@uab.cat
}

\section{RESUMEN}

Se analiza en este trabajo la presencia de lo americano en las seis ediciones del Diccionario de la lengua castellana de la Real Academia Española publicadas entre 1817 y 1852 (DRAE 1817, 1822, 1832, 1837, 1843, 1852). El objetivo se centra en indagar la presencia y evolución de todo lo relacionado con América y, en consecuencia, en discernir el tratamiento que recibe este tipo de información en la historia de la lexicografía académica justo en el momento anterior a la apertura de la obra a la colaboración americana en la segunda mitad de siglo XIX.

Palabras clave: americanismo, diccionario, Real Academia Española, siglo XIX

* La investigación necesaria para llevar a cabo este trabajo ha sido posible gracias a las ayudas del Ministerio de Ciencia, Innovación y Universidades (FFI2014-51904-P, PGC2018-094768-B-I00), y al apoyo de la Generalitat de Cataluña para el «Grupo de Lexicografía y Diacronía» (2017 SGR1251).

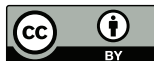

https://doi.org/10.18800/lexis.202101.002 
America in the Diccionario de la lengua castellana of the Real Academia Española (1817-1852)

\section{Abstract}

This work analyses the presence of information related with America in the six editions of the Real Academia Española Diccionario de la lengua castellana published between 1817 and 1852 (DRAE 1817, 1822, 1832, $1837,1843,1852)$. The objective is focused on investigating the presence and evolution of this kind of information and, consequently, on discerning its treatment in the history of the Academia lexicography just before the opening of the work to the American collaboration in the second half of the 19th century.

Keywords: americanism, dictionary, Real Academia Española, 19th century

\section{El diccionario de la Real Academia Española}

Se inicia la historia del diccionario académico en la primera mitad de siglo XVIII con el $D A u t .{ }^{1} \mathrm{y}$, de manera ininterrumpida, llega hasta principios de siglo XXI como un continuum en permanente evolución y cambio. Uno de los muchos valores del primer diccionario académico, el magnífico DAut., reside en la acogida que proporcionó a las voces dialectales, entre las que figuraban los americanismos, un tema que ha sido tratado por no pocos investigadores (Malaret 1947 y 1967; Morínigo 1964: 221; Salvador Rosa 1985; Werner 1983 y 1984; Bohórquez 1984; Alvar Ezquerra [1986] 1993 y [1987] 1993; Seco 1988; Romero Gualda 1992; Cala Carvajal 2001-2002; Fernández Gordillo 2005-2006; Azorín Fernández 2008; Congosto y Quesada 2009).

\footnotetext{
1 Todos los diccionarios citados se han consultado a través del Nuevo Tesoro Lexicográfico de la Lengua Española (NTLLE). Se cita el Diccionario de autoridades (1726-1739) con la abreviatura $D A u t$. y, cuando se menciona la segunda edición, se utiliza $D A u t$. 1770. El resto de diccionarios académicos se identifican con la sigla $D R A E$ y la fecha de edición (DRAE 1817). También se utiliza el NTLLE para los diccionarios no académicos citados (Nebrija 1495, Terreros 1786-1793, Núñez de Taboada 1825 y Salvá 1846).
} 
Es el objetivo de esta investigación el estudio de la presencia de América en los diccionarios académicos de la primera mitad del siglo XIX en el intento de reconstruir el modelo de revisión y aumento de la lexicografía académica durante un período en el que se publicaron seis versiones de su repertorio léxico (DRAE 1817, DRAE 1822, DRAE 1832, DRAE 1837, DRAE 1843, DRAE 1852)2. Esta reconstrucción se cimenta en la identificación de los cambios verificados en cada nueva edición, tanto en la incorporación de nuevas voces y acepciones como en modificaciones de distinto tipo. La exploración se inicia en la quinta edición del diccionario, publicada en 1817, a la que ya se efectuó una primera aproximación (Clavería Nadal, en prensa), y se detiene en la décima edición ( $D R A E$ 1852) porque la importante reestructuración que experimentan las labores lexicográficas de la Academia a mediados de siglo XIX (Roca de Togores [1861] 1870, García de la Concha 2014, Zamora Vicente $1999)$ produce tres ediciones del diccionario vulgar (DRAE 1869$D R A E$ 1899) que implican un cambio de paradigma lexicográfico, por lo que se considera que la edición de 1852, pese a pertenecer ya a la segunda mitad del siglo XIX, no participó de todas estas transformaciones.

No hay que olvidar, además, que la última de las ediciones investigadas es unos años posterior a la publicación del diccionario de Salvá (1846), una obra en la que se concede especial relevancia al léxico americano (Alvar Ezquerra [1986] 1993: 321; [1987] 1993: 344-345; Seco 1988: 90; Azorín Fernández y Baquero Mesa 2008; Azorín Fernández 2008). Desde esta perspectiva, se impone el cotejo entre el diccionario de Salvá y el $D R A E 1852$ para determinar el grado de aprovechamiento que pudo existir en la obra académica con respecto a la del lexicógrafo valenciano y si su existencia pudo comportar algún cambio en las directrices de las labores lexicográficas de la corporación.

\footnotetext{
2 No se ha considerado la primera edición del siglo (DRAE 1803) por entroncar más directamente con las ediciones dieciochescas del diccionario. Las ediciones académicas analizadas en este estudio se consideran con el suplemento incluido.
} 
Se utilizan en la indagación tres tipos de datos distintos: en primer lugar, el aumento y la supresión de lemas de cada una de las ediciones estudiadas, identificados a partir de las informaciones almacenadas en el recurso Lemateca del DRAE y las bases de datos que lo nutren; en segundo lugar, se han llevado a cabo cotejos manuales entre las distintas ediciones con el fin de reconocer la adición de nuevas acepciones y todo tipo de modificaciones en la microestructura, buen ejemplo de esto último son los trueques en las localizaciones (por ejemplo, Indias por América) a las que me referiré más adelante; en tercer lugar, se ha estudiado la evolución del tratamiento de "lo americano" tomando en consideración el conjunto de voces relacionadas con América que ya formaron parte de la nomenclatura desde el $D A u t .^{3}$.

Todo ello permite establecer la existencia de ciertos patrones de evolución lexicográfica que son los que han regido la evolución general de estos diccionarios y su particular proyección en la información relacionada con América. Utilizo esta denominación (patrones de evolución lexicográfica) para designar aquellos cambios que se impusieron en una edición determinada y que hacen posible caracterizar la deriva que representa cada nueva edición del diccionario. Por las características intrínsecas a la lexicografía tradicional y por la particular forma de elaborar cada nueva revisión de la obra académica, estos cambios se perciben como unas tendencias que no se aplican de manera sistemática e, incluso, pueden generar la existencia de mayor heterogeneidad.

En los diccionarios académicos del siglo XVIII y buena parte del XIX, la expresión de la vinculación de las voces y acepciones con América se encuentra incrustada en la propia definición con precisiones de carácter geográfico del tipo las Indias (occidentales) ${ }^{4}$, América, América meridional, América se(p)tentrional, Nueva España, Perú,

\footnotetext{
3 Este corpus se ha establecido a partir de los elementos léxicos identificados en los trabajos de Bohórquez 1984, Salvador Rosa 1985, Romero Gualda 1992 y Fernández Gordillo 2005-2006. Se ha realizado el seguimiento de la vida de aproximadamente 300 palabras desde el $D A u t$. hasta las ediciones del siglo XIX estudiadas en este trabajo.

4 En oposición a Indias orientales, cp. Luján 2017.
} 
reino del Perú, reino de Méjico, reino de Chile o nuevo reino de Granada (cp. Fernández Gordillo 2006: 62-70). También, el sustantivo indio(s) (Company Company 2019) y el adjetivo indiano/na son portadores de este tipo de información. Tales especificaciones se utilizaron al menos en dos situaciones distintas: en primer lugar, son frecuentes en las realidades propias del otro lado del Atlántico; los mejores ejemplos de este empleo se encuentran en el tratamiento lexicográfico de las denominaciones de plantas y animales americanos (ejemplos 1 y 2).

(1) YUCA. s. f. Cierta raíz parecida à nuestra batata, de que en algunos parages de las Indias se sirven para hacer pan... (DAut. $)^{5}$.

(2) Gallinaza ${ }^{6}$. Ave que se cría en las Indias Occidentales, mayor que una gallina y menor que un pavo... (DAut.).

En segundo lugar, también se utilizaron las indicaciones geográficas en la definición de instituciones, cargos, monedas, guisos, etc., entre otras realidades propias de América (ejemplos 3 y 4):

(3) PULPERIA. s. f. Tienda en las Indias, donde se venden diferentes géneros para el abasto... (DAut.).

(4) COLUMNARIO [...] 2. adj. La moneda de plata acuñada en Indias con un sello en que están esculpidas las dos columnas y la letra plus ultra (DRAE 1791).

Las precisiones geográficas pueden describir también un uso lingüístico americano, más o menos amplio (ejemplo 5).

(5) AVIADO. En Nueva España es el sugeto á quien se ha suplido dinero ó efectos, para la labor de las minas, y beneficio de la plata (DAut. 1770-DRAE 1869)'.

\footnotetext{
5 Se marcan en negrita los fragmentos a los que se está haciendo referencia para su mejor identificación. En general, no se incluye en las citas literales de los diccionarios académicos la correspondencia latina.

6 Cuando el lema figura en versalita, se corresponde con una subentrada. Esta práctica aparece desde el DAut. hasta el DRAE 1822, excepto en el DRAE 1791.

7 Se reproduce en el ejemplo la definición del $D R A E$ 1817. Cp. la información de aviador y avío.
} 
Cabe recordar, además, que el adjetivo indiano/na (cp. Luján 2017) se usa en el DAut., en algunas ocasiones, junto a sustantivos como lenguaje/voz/palabra para indicar los vocablos que proceden de alguna lengua indígena americana o que se habían formado con una base de esta procedencia ${ }^{8}$ (ejemplos 6 y 7).

(6) CABUYA. s. f. La cuerda hecha de hilo de pita. Es voz usada en Andalucía, y tomada del lenguage Indiano... (DAut.).

(7) CACAO. Voz Indiana. Fruta menor que almendra, aunque mas gruessa y redonda: la cáscara delicada... (DAut.).

Desde 1780, las ediciones del diccionario académico en un solo volumen mantienen en lo básico este tratamiento de la información, aunque se van introduciendo algunos cambios. Además, y como se observará posteriormente, algunas voces relacionadas con América pueden aparecer o incorporarse en el diccionario sin ningún tipo de mención a su vinculación transatlántica.

Las ediciones que ahora se someten a una mirada escrutadora no se distinguen por una gran ampliación léxica, al contrario, algunas de ellas, desde este punto de vista, comportan una aportación extremadamente pobre, por lo que no son esperables modificaciones de calado y menos en el tema que se pretende estudiar. Además, aunque en esta etapa la atención que dispensa el diccionario a América y al léxico americano es muy secundaria, no hay que olvidar que, desde el punto de vista externo, coincide con las independencias de la mayoría de territorios americanos, con lo que las relaciones entre América y la antigua metrópoli se distanciaron enormemente. Se concibe esta investigación como un paso necesario para el análisis de las ediciones de finales de siglo XIX (DRAE 1869, DRAE 1884, $D R A E$ 1899) en las que, por diversos motivos, la atención al léxico propiamente americano empezará a adquirir mayor relevancia.

\footnotetext{
8 Cp. caoba, chasqui, embixar, escaupil, tambo, zara. También aparecen estas indicaciones referidas a una determinada acepción en empacarse 2 y topo 3.
} 


\section{La presencia de América en el diccionario}

Como ya se ha señalado, los diccionarios que se constituyen en objeto de análisis no destacan por su ampliación léxica9. De todas las ediciones estudiadas (Clavería Nadal 2019), la quinta (DRAE 1817) es la que mayor incremento de lemas y cambios comprende. El resto manifiesta un aumento que queda muy por debajo de las cifras de esta edición. La octava (DRAE 1837) es la que menos incorporaciones de lemas registra, pese a ello reviste cierto interés respecto al tema analizado en esta investigación.

Las tres primeras ediciones (DRAE 1817-1832) se caracterizan, además, por la eliminación de materiales lexicográficos de variado tipo (Clavería Nadal 2019: 16-17). Se suprimen entradas destinadas a voces anticuadas, en lo fundamental variantes formales, y otros elementos como los participios pasados ${ }^{10}$. Este tipo de modificación denota una transformación de las concepciones lexicológica y lexicográfica en las que se fundamentaba el diccionario académico, pues su meta se centró en conseguir una obra sustancialmente distinta — “más manejable” según las propias palabras de la corporación- y con una reducción del número de páginas. No hay que olvidar que, paralelamente, la Academia consideró la elaboración de un diccionario manual (Clavería Nadal 2020). En el terreno de las modificaciones, estas tres primeras ediciones contienen cambios de distinto signo en las definiciones. La quinta edición entraña una reforma de mayor profundidad $\mathrm{y}$, aunque se adoptaron algunas

\footnotetext{
9 Según los datos que pueden consultarse en Lemateca del DRAE, las cifras de adiciones de lemas son las siguientes: 1252 (DRAE 1817), 424 (DRAE 1822), 332 (DRAE 1832), 267 (DRAE 1837), 530 (DRAE 1843) y 656 (DRAE 1852). Una primera caracterización de cada una de estas ediciones puede encontrarse en los trabajos reunidos en Clavería Nadal y Freixas Alás (2018) para el DRAE 1817; Terrón Vinagre (2019), y Terrón Vinagre y Torruella Casañas (2019a y 2019b) para el DRAE 1822; Carriet Valiente (2017) para el $D R A E$ 1832; Julià Luna (2019) para el DRAE 1837; Freixas Alás 2019 para el DRAE 1843; y Buenafuentes de la Mata (2019) para el DRAE 1852. Una visión general puede leerse en Clavería Nadal (2019).

10 Según Lemateca del DRAE, las supresiones alcanzan las cifras de 822 (DRAE 1817), 2323 (DRAE 1822) y 6395 (DRAE 1832), v. sobre esta cuestión Carriet Valiente (2017), Clavería Nadal (2020), Jiménez Ríos (2018a, 2018b, 2018c, 2018d y 2019), y Terrón Vinagre y Torruella Casañas (2019b).
} 
medidas novedosas, fue realizada con prisas $(\mathbb{S} 2.1)$. En las dos ediciones siguientes, se tiende al acortamiento de la información lexicográfica con el propósito de lograr una reducción física de la obra ( $\int \mathbb{S} 2.2$ y 2.3 ). La octava edición comporta una enmienda extremadamente pobre, aunque parece involucrar una colaboración procedente del otro lado del Atlántico ( $\ 2.3$ ); las dos ediciones siguientes (v. $\int \mathbb{S} 2.4$ y 2.5 ) implican el inicio de cierta recuperación en el aumento con respecto a las ediciones precedentes.

Cada una de las ediciones sometidas a análisis tiene su propia idiosincrasia e imprime una huella, más o menos profunda, en el devenir de la obra. Hay que tener en cuenta, sin embargo, que, como los cambios introducidos no son sistemáticos, se van solidificando distintas capas de forma que llegan a convivir en el diccionario materiales de épocas diferentes en una singular amalgama no siempre fácil de desentrañar.

\subsection{DRAE 1817}

Aunque se ha dedicado ya un pequeño estudio a la presencia de América en la quinta edición del diccionario (Clavería Nadal, en prensa), se completará aquí el análisis realizado anteriormente con una reconsideración y ampliación de los datos.

Sin ninguna duda, uno de los aspectos más relevantes de esta edición reside en la particular enmienda de las voces pertenecientes a la historia natural, una actuación de la que queda constancia en el prólogo. La revisión conlleva la ampliación de entradas y acepciones pertenecientes a esta esfera y, muy especialmente, la reescritura de la definición de los lemas que ya albergaba el diccionario (Clavería Nadal 2016: 70-88 y 2018; Gómez de Enterría 2018). El alcance de la revisión fue relativamente amplio, aunque, por supuesto, no fue exhaustivo.

Tanto las voces añadidas (Clavería Nadal, en prensa, $\mathbb{S} 2.1$ ) como las enmendadas destacan por el hecho de que en las definiciones se consignó la vinculación del animal o la planta a su lugar de origen. En palabras de Gómez de Enterría (2018: 292-293), “la corrección 
se ha tratado de llevar a cabo siguiendo los principios de la sistemática linneana", lo que implicó la "supresión casi general de las definiciones por comparación que tan frecuentes eran en la edición de 1803". Se usaron para ello unos patrones definitorios bastante estables en los que constan precisiones geográficas del tipo "de la América", "originaria de Indias/de América", "indígena de Nueva España/ de América”, etc. Estas caracterizaciones suelen aparecer en la parte inicial de la definición (ejemplos 8 y 9).

(8) PAZOTE. s. m. Planta originaria del Perú, y cultivada en algunas partes de España. Crece hasta la altura de un pie; tiene las hojas estrechas y crasas... (DRAE 1817: suplemento).

(9) PITPIT. s. m. Ave indígena de América. Es de unas cuatro pulgadas de largo, de color azul, con la parte superior de la cabeza, el pico, las alas y la cola negra. Se alimenta de semillas é insectos (DRAE 1817).

Es relativamente frecuente que en la historia de la lexicografía académica la definición se mantenga con las mismas características desde el $D A u t$. hasta la cuarta edición del diccionario en un solo volumen (DRAE 1803) y en la quinta se produzca una remodelación de la microestructura siguiendo los cauces mencionados (ejemplos 10 y 11 ).

(10) OCOZOL. s. m. El árbol de que en Nueva España se saca el liquidámbar. Es muy grande, hermoso y poblado de ramas, cuyas hojas se parecen á las de la yedra. Tiene la corteza espesa y cenicienta, la qual al cortarse echa una resina liquida, clara y que tira á roxa, que por ser muy odorífica y suave se llama liquidámbar (DAut.-DRAE 1803).

(11) OCOZOL. s. m. Árbol de veinte á treinta pies de altura, é indígeno de Nueva España y de otras partes de la América setentrional. Tiene las hojas divididas en gajos, las flores sin hojas, y por fruto una caja aovada y leñosa. De este arbol se saca el bálsamo conocido con el nombre de liquidambar (DRAE 1817).

La extensión de este patrón definitorio explica que algunas definiciones de animales y plantas que no mencionaban la relación con América, la adquieran, tal como puede observarse en los lemas drago, en el que se incluye la mención a América y Canarias (Corbella 2016: 117-118), y nigua (ejemplos 12-15). 
(12) DRAGO. s. m. Árbol, cuyo tronco es alto como el de un pino, su madera dura, su corteza desigual, sus hojas grandes y largas en figura de hoja de espada, el fruto es arracimado, y estando maduro es de color cerúleo y de un gusto ácido, la goma roxa que destila, es la que llaman sangre de DRAGO (DRAE 1803).

(13) DRAGO. s. m. Árbol [...]. Se cria en varias partes de América y en las Islas Canarias, de donde se trae la sustancia llamada SANGRE DE DRAGO, que fluye de su tronco en tiempo de canícula (DRAE 1817).

(14) NIGUA. s. f. Especie de pulga pequeñita indiana, que como ladilla se pega, especialmente á los pies, é introduciéndose entre cuero y carne... (DRAE 1803).

(15) NIGUA. s. f. Insecto indígeno de la América. Es de menos de media línea de largo, y muy parecido á la pulga... (DRAE 1817).

Cabe advertir que, con la redefinición de los nombres de animales y plantas (Gómez de Enterría 2018: 292 y ss.) según nuevos parámetros científicos, la quinta edición consiguió que la información adquiriera cierta homogeneidad. No resulta difícil, sin embargo, encontrar ejemplos en los que no se aplicó tal reforma (ceiba, ocozoal, tabaco, etc.) y la información se mantuvo siguiendo esquemas que se remontan a ediciones anteriores. Incluso hay casos en los que la enmienda implicó que la explicitación de la relación con América desapareciese (aguacate, caimán, quetzale). Pese a estas heterogeneidades, la tendencia a generalizar el patrón de definición que menciona el origen fue relativamente general.

Se empieza a percibir también que la mención a América en las definiciones puede desaparecer debido a la imposición de un férreo sistema de remisiones, un tipo de cambio que se realiza con cierta frecuencia en las ediciones de 1817 y de 1822 (Muñoz Armijo 2018, Terrón Vinagre y Torruella Casañas 2019a ${ }^{11}$. Por ejemplo, cabuya se definía como "Yerba que se cria en las Indias occidentales, y sirve para hacer cuerda” (DRAE 1803) y en la quinta edición se transforma en "Planta. Lo mismo que PITA" (DRAE 1817). Igualmente

\footnotetext{
11 En el prólogo de la quinta edición, se señala que se han corregido algunas inexactitudes en las remisiones y, aunque se subsanaron algunos errores, también se generaron otros (Gómez de Enterría 2018: \12.5.5).
} 
ocurre en manatí (con remisión a vaca marina, cp. De Beni 2014: 107-108), árbol de María (s. v. maría, con remisión a calambuco) o semioulpa (con remisión a zarigüeya).

Fruto de la reescritura de la definición en las denominaciones de animales y plantas son las modificaciones de las localizaciones americanas en las que se observa cierta preferencia por "América” en sustitución de "Indias"12. Conviene destacar, además, la aparición de la abreviatura $p$. de Amér. (provincial de América) en la entrada maguey, algo inusual en el proceder académico del momento. Se trata de un lema que ya se encontraba en el $D A u t$. y que se mantuvo con la misma información hasta el $D R A E 1803$ (ejemplo 16). En la edición siguiente, la definición es sustituida por una remisión (ejemplo 17) a la que acompaña la abreviatura mencionada.

(16) MAGUEY.s. m. Árbol que se cría en las Indias, de la altura de veinte pies, y del gruesso de un brazo... (DAut.).

(17) MAgUEY. s. m. p. de Amér. Planta. Lo mismo que PITA (DRAE 1817).

Tanto pita como maguey son sinónimos documentados en los textos desde el siglo XVI. La abreviatura de la quinta edición parece reflejar la restricción en el uso de este último indigenismo $\left(D E C H^{13}\right.$, s. v.), una restricción que volverá al diccionario más adelante y en un marco de tratamiento de los americanismos bastante diferente ${ }^{14}$. En aras de la homogeneidad del diccionario, esta abreviatura fue eliminada en la edición de $1832^{15}$.

12 Esto ocurre en alaqueca, anacardo, audiencia pretorial, bejuco, borrachera, búcaro, cacao, caoba. contrayerba, coracha, chicozapote, chirimoya, danta, gallipavo, hutia, mamey, mate, nigua, paca, papagayo, pasionaria, pita, pito, plátano, yuca, zapote, zarzaparrilla de Indias (cp. Fernández Gordillo 2006: 300).

13 Diccionario crítico etimológico castellano e hispánico.

14 Maguey aparece con la marca pr. Cuba (DRAE 1899-1914), Cuba y Méj. (DRAE 1925) y Amér. (DRAE 1936-Diccionario de la lengua española [DLE] 2014) y conservación de la equivalencia geosinonímica con pita.

15 Cp. Fernández Gordillo 2006: 309. Este tipo de abreviatura aparece ocasionalmente: acal y acignatarse figuran con la abreviatura Americ. en la segunda edición del DAut. (1770); en ambos casos se trata de lemas incorporados en aquel momento (cp. Fernández Gordillo 2006: 46, nota 25; 242, donde la interpreta como una abreviatura que indi- 
Cabe señalar, además, que, en las voces pertenecientes a otras esferas semánticas, no se perciben tantos cambios en la definición como los que registran los elementos léxicos de las ciencias naturales, con lo que esta puede mantener la información sin alteraciones al menos hasta la décima edición (por ejemplo, mechoacán, mitote, orejeras 3 , orejones 4 , piragua, etc.).

\subsection{DRAE 1822}

Como se ha indicado anteriormente, las dos ediciones siguientes comportan un cambio sustancial en la base lexicológica del diccionario académico y ello se trasluce en un aumento muy reducido acompañado de una abundante supresión de lemas.

La enmienda del DRAE 1822 registra algunas nuevas denominaciones de animales, plantas y minerales (Terrón Vinagre 2019: 1335-1336), de las que chirimoyo y turbinto (ejemplos 18 y 19) son caracterizadas como plantas americanas; atrás queda la amplia revisión de este tipo de voces de la quinta edición.

(18) CHIRIMOYO. s. m. Árbol de América bastante corpulento y ramoso, que tiene las hojas verdes, la flor sumamente olorosa, y de solas cuatro hojas muy gruesas, ... (DRAE 1822: suplemento).

(19) TURBINTO. s. m. Árbol grande y hermoso originario del Perú, cuyas hojas, aunque mas estrechas, imitan a las del lentisco, por lo cual le llaman tambien lentisco del Perú ${ }^{16}$. Su flor... (DRAE 1822).

Las supresiones de entradas de esta edición superan las dos mil $\mathrm{y}$ afectan fundamentalmente a las voces y formas antiguas de las que estaba repleto el diccionario (un $80 \%$ de las supresiones según Terrón Vinagre y Torruella Casañas 2019b: 112). No se omiten

caría la "procedencia originaria de un vocablo"); desempacarse y embixar muestran la abreviatura p. Amér. y p. Ind., respectivamente, en el DRAE 1780. En desempacarse, la abreviatura se corresponde con la precisión "Es voz americana", que constaba en el $D A u t$. Estas abreviaturas son suprimidas en el DRAE 1791 en desempacarse y embixar; y en el $D R A E 1803$ se prescinde de ellas en acal y aciguatarse (cp. Fernández Gordillo 2006: 292).

16 Lentisco del Perú (s. v. lentisco) se incorpora en el DRAE 1884 con remisión a turbinto, a la par que desaparece la referencia sinonímica en la entrada lentisco. 
voces relacionadas con América, salvo algún caso aislado (cuarango ${ }^{17}$, semivulpa).

Los cambios en la definición registrados en la sexta edición (Terrón Vinagre y Torruella Casañas 2019b) son escasos. Pese a ello, se pueden identificar algunas modificaciones en la formulación de las ubicaciones americanas. En alguna ocasión, se sustituye América por Nueva España (almendrón) o viceversa (achiote, ánime); Perú se puede generalizar como América (calaguala) y no falta algún ejemplo de América en sustitución de Indias (canchelagua-

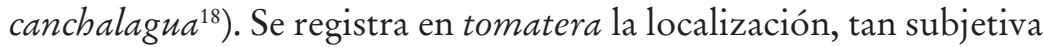
(Forgas Berdet y Herrera Rodrigo 2002, Rodríguez Barcia 2008) y parcialmente inexacta, de nuestra América: "es yerba originaria de nuestra América”. Se identifican, además, un par de casos (batata y tabaco) en los que con la redefinición se elimina la mención a la procedencia americana de la planta, un procedimiento que adquirirá mayor alcance en la edición siguiente.

Asimismo, se verifica un cambio de definición en el lema cachupin, una voz que ya se encontraba en la nomenclatura del DAut. (ejemplo 20), que va adelgazando su información de forma progresiva (ejemplo 21) y que en la sexta edición sufre un pequeño cambio en la definición con permuta de Indias por América (ejemplo $22)^{19}$. Las modificaciones, sin embargo, parecen aisladas y el uso del topónimo América se registra en una proporción muy similar a la de la edición anterior.

(20) CACHUPIN. s. m. El Español que passa y mora en las Indias, que en el Pirú llaman Chapetón. Es voz trahída de aquellos Países y mui usada en Andalucía, y entre los comerciantes en la carrera de Indias (DAut.).

(21) CACHUPIN. s. m. El español que pasa y mora en Indias, donde se llama GACHUPIN. Es voz muy usada en Andalucía (DRAE 1780DRAE 1817).

\footnotetext{
17 Seguramente la supresión pudo ser un error, puesto que vuelve a aparecer en la nómina académica más adelante.

18 Esta entrada, presente desde el DAut., no había cambiado en el DRAE 1817.

19 Sobre la historia de esta palabra en el siglo XIX, v. García Godoy 1998: 164-175.
} 
(22) CACHUPIN. s. m. El español que pasa á la América, y se establece en ella (DRAE 1822).

La amplia reestructuración del sistema de remisiones y de la definición sinonímica (Terrón Vinagre y Torruella Casañas 2019a) comporta la pérdida de especificaciones que acompañaban inicialmente a la equivalencia léxica, como ilustran los ejemplos 23-25 (cp. Fernández Gordillo 2006: 304).

(23) ZARA. s. f. El trigo de las Indias, que llamamos maíz. Es voz Indiana... (DAut.).

(24) ZARA. s. f. El trigo de las Indias que llamamos maiz (DRAE 1780-1817).

(25) ZARA. s. f. MAIZ (DRAE 1822) ${ }^{20}$.

Además, y en el intento de mejorar el funcionamiento del sistema de remisiones, en algún caso la definición es sustituida por una simple equivalencia (pimiento de las Indias y jiquilete) o al revés (ipecacuana ${ }^{21}$ ).

En conclusión, el diccionario publicado en 1822 supone un giro notable en los presupuestos lexicológicos y lexicográficos del quehacer académico, y ello se traduce en unas cifras de adiciones y supresiones de lemas en las que las segundas superan con creces a las primeras. Con todo ello, se abandona, en parte, la concepción del diccionario como depósito de material lingüístico arcaizante (Clavería Nadal 2019: 23-24; 2020: 30-36). En la materia estudiada, la sexta edición no aporta ninguna novedad, la ampliación de las voces de una forma u otra relacionadas con América es muy constreñida y las intervenciones en las entradas también lo son.

\subsection{DRAE 1832}

Cuando se produce la nueva edición del diccionario, diez años después de la última, la situación política y las relaciones de la

20 La denominación “trigo de Indias” desaparece también en maíz, v. más adelante.

21 En este caso se resuelve un círculo vicioso porque bejuquillo e ipecacuana se remitían mutuamente en el DRAE 1817 y en ninguna de las dos entradas constaba la definición de la planta. 
metrópoli con América habían cambiado sustancialmente pues los procesos de independencia habían dado origen a las distintas naciones americanas. Sin embargo, no parecen encontrar reflejo estos acontecimientos tan trascendentales en la enmienda llevada a cabo en la séptima edición.

En esta, se continúa con los presupuestos lexicográficos aplicados en la edición anterior de modo que la nueva versión experimenta un nuevo descenso en el número de entradas del diccionario (v. nota 10). Todo el peso de la rectificación se concentra en la reducción de la obra tanto en la macroestructura con la eliminación de lemas, mayormente de elementos de carácter gramatical (participios y verbos reflexivos), como en la microestructura, en especial, con el acortamiento de las definiciones.

En el limitadísimo aumento de lemas de la séptima edición, destacan las palabras relacionadas con las ciencias naturales — 44 según los datos de Carriet Valiente (2017: 43-44) —; dentro de estas, únicamente damasquina (ejemplo 26) establece vínculo con América en la definición.

(26) DAMASQUINA. f. Planta anua, originaria de Méjico, que crece hasta la altura de dos piés: sus tallos son rollizos, sus flores solitarias ... (DRAE 1832).

En el resto del aumento de entradas no se perciben relaciones explícitas con América a través de las definiciones. Cabe reparar, sin embargo, en la presencia de algunos derivados (Carriet Valiente 2017: 47-49) que podrían ser significativos. El primero es cafetal, un derivado de café que viene a completar la familia de este sustantivo en el diccionario. En sus orígenes, la voz aparece ligada al cultivo del café en América y, a los ejemplos de su presencia en textos periodísticos dieciochescos relacionados con Cuba (Álvarez de Miranda [2010] 2016: 41), se puede añadir el que aparece en la Descripción geográfica y estadística de la provincia de Santa Cruz de la Sierra de Francisco Viedma Narváez $\left(1788, C D H^{22}\right.$ ) al referirse a

${ }^{22}$ Corpus del Nuevo diccionario bistórico. 
las tierras ocupadas por los indios sirionós en la actual Bolivia — “en unos espesos montes que median para las misiones de Moxos, cuyos terrenos ofrecen la mayor fertilidad para plantíos de cacahuales, cafetales y algodonales"-, un texto que ofrece tres preciosos ejemplos de derivación con el sufijo - al con el mismo valor semántico y que es testimonio de la extensión del cultivo del café en América del Sur desde mediados de siglo XVIII (Soux 2016). Hay que considerar, además, la incorporación del lema caníbal (con remisión a caribe), de documentación muy antigua en los textos americanistas. Finalmente, se podría agregar el deverbal desemboque (con remisión a desembocadero en el diccionario), una voz que aparece documentada en los textos desde el siglo XVII (documento peninsular de 1619 en el CDH) y que está atestiguada en textos americanos desde 1684 (CDH), con referencia generalmente a un río o a otros accidentes geográficos, y en alternancia sinonímica con desembocadura y desembocadero, sustantivos que presentan similares características documentales.

De forma muy aislada, se ha registrado en la séptima edición una modificación en la localización geográfica en la definición de laca (compárense los ejemplos 27 y 28), en la que se sustituye "Nueva España”, una entidad territorial que había desaparecido, por una denominación tradicional, que no refleja los cambios políticos producidos en los años anteriores.

(27)| LACA. s. f. Especie de goma resinosa muy encarnada que elaboran sobre las ramillas de un árbol de la India ciertos insectos, y que regularmente se trae en granos pegados á los palillos de dichas ramillas. Tambien se cria en el reino de Nueva-España... (DRAE 1822).

(28) LACA. s. f. Especie de goma resinosa muy encarnada que elaboran sobre las ramillas de un árbol de la India oriental y del reino de Méjico ciertos insectos, y que regularmente se trae en granos pegados á los palillos de dichas ramillas... (DRAE 1832).

Del mismo modo el adjetivo indiano/na, utilizado en el DAut. para indicar tanto la procedencia de la palabra (e. g. cacao) como para describir realidades propias de América (e. g., saxifraga, pipian, 
nigua), tiende a desaparecer ${ }^{23}$ o a ser sustituido por una localización más restringida o precisa como en el caso de tambo (ejemplos 29-31):

(29) TAMBO. s. m. Meson, ò venta. Es voz Indiana. Lat. Diversorium. Solorz. Polit. lib. e. cap. 13. Y que los Corregidores visiten las ventas, mesones, o tambos (DAut.).

(30) TAMBO. s. m. Meson, ó venta. Es voz indiana (DRAE 1780-1822).

(31) TAMBO. m. Meson ó venta. Es voz del Perú (DRAE 1832-1869).

Destaca la séptima edición por dos actuaciones que inciden en la definición de las voces bajo análisis: por un lado, se produce una merma general de la información lexicográfica (Carriet Valiente 2017: 54 y ss.) con el fin de obtener la disminución del diccionario (Clavería Nadal 2019: 24-26; 2020: 36-40); por otro lado, se verifica una nueva revisión de las voces de historia natural, aunque de signo distinto a la de la quinta edición, pues, en aquella ocasión intervinieron especialistas en la materia, mientras que en 1832 el grueso de la enmienda corrió a cargo del académico J. Musso y Valiente y los objetivos fueron otros (Clavería Nadal 2016: 95-109).

La revisión y reducción emprendidas en las voces de esta área temática comporta, en muchas ocasiones, la desaparición de la localización americana, una información que frecuentemente había introducido la quinta edición y, en 1832, su eliminación parece una simple forma de acortar el contenido de la entrada. Así ocurre con ocozol (ejemplo 11), voz en cuya definición se eliminan las localizaciones de Nueva España y América setentrional (ejemplo 32, cp. Fernández Gordillo 2006: 309):

(32) OCOZOL. m. Árbol de veinte á treinta piés de altura, que tiene las hojas divididas en gajos, las flores sin hojas, y por fruto una caja aovada y leñosa (DRAE 1832).

\footnotetext{
23 Las voces que en el $D A u t$. aparecían descritas como indianas suelen perder esta especificación ya en el primer diccionario en un solo tomo (DRAE 1780), aunque en algún caso puede mantenerse hasta más adelante (cp. topo 3).
} 
Otro ejemplo de las intervenciones que se producen en la séptima edición se encuentra en los cambios que registra el sustantivo llama (ejemplos 33 y 34), también con supresión de la información geográfica ${ }^{24}$, que no resulta de la reelaboración de la definición anterior, pese a que ambas comparten el clasificador cuadrúpedo.

(33) LLAMA [2]. s. f. Cuadrúpedo indígeno de la América meridional. Tiene vara y media de altura, el cuerpo cubierto de una especie de lana mas larga por el pecho y por las ancas, el cuello largo y erguido, la cabeza chica, y los pies con pezuña, que solo cubre la mitad de los dedos. Es animal de carga muy manso, y el único que los naturales del Perú antes de la conquista habian domesticado. Su carne es comestible, sana y delicada. Camelus lacma (DRAE 1817-1822).

(34) LLAMA. f. [...] \| m. Cuadrúpedo del género del camello, con los dedos separados y el lomo liso, del tamaño de un ciervo, y de pelo áspero y castaño. Lacma (DRAE 1832).

La eliminación de las localizaciones afecta tanto a América ${ }^{25}$ como a otro tipo de acotaciones geográficas: en pulque, se suprime Nueva España; en aceite de palo (s. v. aceite), se prescinde de Perú, Chile y Tierra firme; en quina, del adjetivo peruana; en murtilla $y$ patagua, de la referencia a reino de Chile, etc. La exclusión de la ubicación geográfica es relativamente frecuente cuando la entrada es extensa; por contra, cuando esto último no es así, se mantienen las geolocalizaciones sin ningún cambio; por ejemplo, la entrada anterior a ocozol (ejemplo 32) es ocozoal — "Serpiente que se halla en el reino de Méjico, que tiene la cabeza de víbora y el vientre blanco, que tira algo á rojo. Ocozoaltus serpens"- y, a diferencia de aquella, no sufre ninguna modificación ${ }^{26}$.

La reducción suele conseguirse con la omisión de la localización geográfica y también con la supresión de los usos de la planta, algo

${ }^{24}$ La apreciación geográfica se recupera en el DRAE 1899 como «América meridional».

25 Cp. madreperla, maí, manglar, murtilla, nicociana, nigua, oca 2, ocozol, paca 1, paco, pájaro resucitado, pájaro mosca (s. v. pájaro), papagayo, parcialidad, pasionaria, patata, pavo, perico ligero (s. v. perico), pimiento, picacureba, pita 1, pita 2, pito 3, pitpit, plátano 1 , plátano 3, pulque, quina, sándalo 2.

${ }_{26}$ En Clavería Nadal (2016: 98), pueden leerse las directrices que dio M. Fernández de Navarrete a J. Musso para que este efectuase la enmienda. 
muy característico de la definición ilustrada bien presente hasta la quinta edición del diccionario (Clavería Nadal y Paz Afonso 2018). Ejemplo de ello puede hallarse en ocozol (ejemplos 11 y 32) y patagua (ejemplo 35). También se eliminan las explicaciones sobre la motivación de la denominación, un tipo de apreciaciones muy características del discurso lexicográfico del $D A u t$. que va desapareciendo progresivamente; así, en la entrada maíz se omite "Llámase trigo de Indias por haber venido de América" (DRAE 1817-1822) en $1832^{27}$. Estas reducciones se produjeron sobre todo cuando la definición era extensa, con lo que esta forma de proceder generó mayor heterogeneidad entre las distintas definiciones que albergaba el diccionario y rompió la relativa homogeneidad en la definición de animales y plantas conseguida en la quinta edición del diccionario. Si en esta se había establecido un patrón definitorio en el que se distinguían los animales y las plantas por ser indígenos de España o de América, las dos ediciones siguientes introducen modificaciones que tienden a borrar este tipo de caracterización. Así, especificaciones como “indígena de España” fueron motivo de supresión, al menos en las primeras letras del abecedario, en el $D R A E 1822$ (Terrón Vinagre y Torruella Casañas 2019b: 136-137) y, en la séptima edición, el acortamiento implica la desaparición de estas especificaciones en árboles, plantas y animales inicialmente definidos como indígenos de América (ejemplos 35-38); además, se registra también la supresión de otras informaciones como la que aparecía en oca (ejemplo 37), en cierta medida redundante por la existencia de caví como entrada desde el DRAE $1803^{28}$.

(35) PATAGUA. s. f. Arbol indígeno del reino de Chile, en donde crece en sitios cenagosos hasta la altura de veinte á veinte y cinco pies. Tiene las hojas aovadas, mas ó menos largas, y las flores blancas. Su

\footnotetext{
27 Cp. la evolución de zara mencionada anteriormente.

28 La referencia a caví en la definición de oca se remonta al DAut. Por tanto, aunque el lema se añade en 1803, la palabra ya constaba en el repertorio académico desde sus inicios; así, las primeras ediciones del diccionario en un solo volumen sistematizan en muchas ocasiones la información que ya constaba desde el primer repertorio académico (Aliaga Jiménez 2000, Fernández Gordillo 2006).
} 
madera, que es blanca, poco dura y ligera, la emplean los naturales para muebles y otras obras (DRAE 1822).

(36) PATAGUA. f. Árbol que crece en sitios cenagosos hasta la altura de veinte á veinte y cinco piés. Tiene las hojas aovadas mas ó menos largas, y las flores blancas. Su madera es blanca, poco dura y ligera (DRAE 1832).

(37) OCA [2]. Planta indígena de la América, que echa un tallo ramoso vestido de hojas compuestas de otras, y las flores amarillas. La raiz de esta planta, conocida en algunas partes con el nombre de caví, se come cocida, y con este objeto se cultiva esta planta en gran abundancia en el reino del Perú y otras partes ( $D R A E$ 1822).

(38) OCA [2]. Planta que echa un tallo ramoso vestido de hojas compuestas de otras, y las flores amarillas (DRAE 1832).

Habría que estudiar con detalle la distribución de los cambios en las distintas letras del diccionario, pues posiblemente no fueron enmendadas por igual. Dentro del corpus de voces cotejadas, las modificaciones se verifican, en especial, a partir de la letra $m$ y son bastante frecuentes en la letra $p$. En cualquier caso, la actuación no fue sistemática, con lo que este tipo de caracterización se elimina en algunas entradas y se mantiene en otras (ejemplo 39).

(39) LATAZ. s. m. Cuadrúpedo indígeno de América y Asia. Es de unos tres pies de largo,... (DRAE 1817-1884).

En suma, la séptima edición del diccionario, con su interés por la compresión de la obra, supone cierta reducción de la presencia explícita de América en la obra académica, en especial en las informaciones contenidas en la microestructura.

\subsection{DRAE 1837}

La octava edición del diccionario conlleva una ampliación léxica aun más limitada que la de las ediciones precedentes; pese a ello, es una edición que reviste cierta importancia para el objetivo de esta investigación. Como ya señalé en un estudio precedente (Clavería Nadal 2016: 110), en la breve acta de la junta académica celebrada el jueves 15 de octubre de 1835, se consigna la ocupación a la que se dedicó la Academia: "se leyeron varias observaciones sobre el Diccionario 
remitidas por un americano, y se llegó á la palabra Jalisco" ${ }^{29}$ (Actas). Se podría suponer, por tanto, que en estas observaciones pudieran constar voces y acepciones relacionadas con América que se traspasaron a esta edición del diccionario y ciertamente se pueden descubrir algunos datos de interés; la simple mención de la palabra jalisco apunta hacia esa dirección.

Sin ninguna duda, uno de los ejemplos más relevantes y, a la vez, enigmáticos del aumento de esta edición se encuentra en la palabra volanta. Se trata de una incorporación del $D R A E 1837$ en la que aparece una marca diatópica que restringe la palabra a una zona de América (ejemplo 40), una práctica no habitual en la lexicografía académica $^{30}$.

(40) VOLANTA. f. prov. de la Habana. Especie de calesín muy ligero (DRAE 1837).

La forma volante se registra ya en el Diccionario provincial de voces cubanas de Esteban Pichardo, publicado por primera vez en 1836 con la información siguiente (ejemplo 41):

(41) VOLANTE. N. s. f. Una de las especies de carruages de lujo usados en la isla, igual al quitrin, con la diferencia que la parte superior es firme, á modo de caleza; cuyo nombre le daban antes en tierradentro. $\|$ v. CHUPA (Pichardo 1836) ${ }^{31}$.

También, el vocablo forma parte de la lista de setenta cubanismos que acompaña al Viaje de Perico Ligero al país de los moros del

29 El lema jalisco no experimenta ningún cambio en esta edición del $D R A E$.

30 Como se ha observado al comentar la entrada maguey en el DRAE 1817 y en los ejemplos citados en la nota 14, este tipo de abreviaturas aparecen en el diccionario de manera muy aislada y siempre acabaron por desaparecer antes del $D R A E 1884$.

31 Quitrín forma parte también de la nomenclatura del Diccionario provincial de voces cubanas y contiene una información más detallada que involucra la comparación con volante: "Especie de silla volante de dos ruedas y dos barras: distínguese de la volante en que la parte superior es de cuero, flecsible por medio de resortes para bajar ó cerrar el fuelle con el objeto de evitar el agua y el sol, ó bien para descubrirse; de cuya ventaja carece la volante, que tiene el cielo firme. Aunque estos dos carruages son de uso comun en toda la isla, los quitrines se estiman de mayor lujo y comodidad, mientras que las volantes van desapareciendo" (Pichardo 1836). Esta voz se incorpora a la nomenclatura académica en 1884 con la especificación de ser un "carruaje [...] usado en América”. 
mejicano A. López Matoso, un diario de viaje escrito probablemente entre 1816 y 1820 (López Morales 1971, Zamora Munné 2001). Este texto registra las variantes bolantas y bolantes (ejemplo 43), el primero se atribuye al habla cubana y el segundo, a los mexicanos.

(43) Bolantas son las q. los guachinangos dicen bolantes (López Morales 1971: 90).

Se establece en esta observación una equiparación entre v/ bolante y v/bolanta ${ }^{32}$ y, al confrontar la información de López Matoso con la de Pichardo, se puede concluir que, en la Cuba de la primera mitad de siglo XIX, coexistieron las dos varientes (volante y volanta).

Aparte de volanta, Julià Luna, en su estudio sobre esta edición, ha identificado la introducción de bambú, chambón y cúbica como lemas nuevos del DRAE 1837 que constan también en la primera edición del diccionario de Pichardo (1836); además, la autora relaciona con América las incorporaciones de calisaya, chambonada, naboría, quinina y las acepciones nuevas introducidas en las entradas de poncho/cha y petaca (Julià Luna 2019) 33 .

Un cotejo exhaustivo de la primera edición de la obra pichardiana con el diccionario académico de 1837 permite añadir a los cuatro precedentes (volante, bambú, chambón y cúbica) tres casos más de posible dependencia: 1) El diminutivo lexicalizado caracolillo aparece como "El CAFÉ CARACOLILLO es el que tiene esta figura; suele

32 Señala López Morales (1971: 95): “En el léxico dialectal de Méjico no encuentro bolantes, sino bolán, volán, «nombre con que se conoce la volanta en Yucatán; carruaje que en otras partes se llama chispa; usual en pueblos y haciendas. VARS. bolán, bolánkoche, volancoché», Santamaría (1959), s. v. volán. Por lo demás, volanta parece ser término conocido en todo Méjico a juzgar por Santamaría, que lo define como «Quitrín descubierto, con varas largas, tirado por una sola bestia»; muy usado por los campesinos. Es quizá el mismo volante [?] de las Antillas. En Cuba no fue carruaje rural, sino urbano, y en contra de lo que dice Acad. (1956), lo hubo también de cubierta desplegable, tal y como se ven en los grabados de la época”.

33 En el caso de chambón existe diferencia entre la información semántica del diccionario de Pichardo ("sinónimo de chapucero", $D E C H$, s. v. chamba) y la del diccionario académico ("El poco diestro en el juego"); las definiciones académicas de chambón y chambonada parecen cercanas a las que ofrece el diccionario de Núñez de Taboada 1825 (Clavería Nadal 2019: 34). 
escogerse y separarse por el mucho aprecio que tiene en la parte occidental" (Pichardo 1836, s. v. café) y podría corresponderse con la nueva acepción del lema caracolillo del $D R A E 1837$ ("Especie de café muy estimado, cuyo grano es mas pequeño que el comun”). 2) Al adjetivo quebrado/da, se agregaron dos acepciones - las dos primeras: “adj. que se aplica al que ha hecho bancarrota ó quiebra” y "el que padece quebradura ó hernia” (DRAE 1837)— que coinciden con el contenido de esta entrada en el diccionario de Pichardo: "El comerciante que se ha presentado á quiebra. Tambien se dice del hacendado que se concursa" y "La persona que padece hernia"34. 3) Por último, en el lema tirante se incorporó la acepción "La tira de piel ó tela con elásticos y hebilla ó sin ellos, que sirve para suspender de los hombros el pantalon. Por ser dos se les nombra comunmente en plural" (DRAE 1837), la cual se corresponde con la voz tirante ("Las tiras de lienzo, seda, piel \& que pasando por sobre los hombros asegura el pantalon”, Pichardo 1836).

Aunque los datos son extremadamente pobres, estas coincidencias llevan a pensar si el propio Pichardo, (quien conocía muy bien la séptima edición del diccionario académico, pues fue uno de los puntos de partida de su Diccionario provincial de voces cubanas $^{35}$ ), podría ser el americano que mencionan las actas académicas. Al revisar el $D R A E$ 1832, pudo haber elaborado una lista de observaciones que pudiera haber hecho llegar a la corporación ${ }^{36}$. Si no fuese así, se debería pensar en la colaboración de un “americano" no identificado, además del posible aprovechamiento

\footnotetext{
34 En orden inverso al DRAE 1837.

35 Las referencias de carácter contrastivo a la información de la séptima edición del diccionario académico se producen a lo largo de todo el diccionario (Pichardo 1836): s. v. bija, bozal, budión, cabrilla, carapacho, cerrero, ciego, corredor, chicharro, chirimoyo, chumacera, espuela, frijol, gro, guacamayo, guayabo, guayacán, horqueta, iguana, jabado, jutía, mais, manatí, manto, maravilla, miel, millo, nigua, ortiga, pimienta, piña, plátano, pucha, quibey, salpicón, tierra y tonina. Implícitamente, la información que consta en chicharo y jabato supone comparación con el DRAE 1832.

36 Se ha consultado a Covadonga de Quintana, directora del Archivo de la Real Academia Española y, de momento, no se ha identificado ningún documento relacionado con las "observaciones" mencionadas en las actas. Sobre la relación de Pichardo y la Academia, v. Werner 1994: 118.
} 
del Diccionario de Pichardo (1836) o de una fuente lexicográfica anterior a este y no conocida por ahora (López Morales 1971: 88; Werner 1994: 110-111).

En el terreno de los cambios en las definiciones ${ }^{37}$, las modificaciones son muy escasas. Destaca la reescritura de pampanilla que figuraba, desde el DAut., como "Cobertura de la decencia ú honestidad que usan los indios, y porque regularmente se forman de pámpanas colgadas alrededor de la cintura, llamaron así los españoles aun las que se hacen de otra cualquier cosa" (DRAE 1832) y que en la octava edición se reduce a "Especie de tonelete que usan los indios por honestidad y decencia" (DRAE 1837). Cabe señalar, además, en cabecilla 2 ("jefe de rebeldes") la supresión de la restricción "Úsase en América”, un detalle de uso que había sido añadido en el $D R A E 1817$ y que en 1837 ya no era adecuado porque este valor se empleaba también en España $(C D H)$.

En cualquier caso, pese a que la revisión que se llevó a cabo para la octava edición fue enormemente reducida, se encuentra en ella un pequeño grupo de voces y acepciones vinculadas con América que la dotan de singularidad y que acrecientan su importancia dado el exiguo número de adiciones que contiene esta edición.

\subsection{DRAE 1843}

La novena edición abarca un aumento mayor de lemas que las tres ediciones anteriores (Freixas Alás 2019) ${ }^{38}$. Se rastrea en este, sin embargo, poquísima presencia de voces relacionadas con América.

\footnotetext{
37 Con el fin de rastrear la presencia de esta contribución he ampliado el cotejo manual entre la edición de 1832 y la de 1837, sin que haya podido hallar mayores evidencias, pues en muchas páginas del diccionario no se introduce ninguna modificación. Se perciben más intervenciones, siempre dentro de ciertos límites, en las palabras que empiezan por $p a-$, en general la supresión de algunas palabras de la definición y también la adición de acepciones.

38 No hay que olvidar que hay unas Reglas para la corrección y aumento del diccionario de 1838 (RAE 1838), pero su contenido no varía con respecto a la última versión del siglo XVIII (Rodríguez Ortiz y Garriga Escrigano 2010) y, más bien, tienen que ver con un nuevo intento de reemprender la elaboración del DAut. (Clavería Nadal 2016: 113-115), por lo que no afecta su consideración al tema estudiado.
} 
Los casos más destacables son, sin ninguna duda, la incorporación de butaca (ejemplo 44), presente en Pichardo (1836), y sabana (ejemplo 45) ${ }^{39}$.

(44) BUTACA. f. Silla grande, muy baja y tendida. Ella y su nombre son de procedencia americana (DRAE 1843).

Butaca es vocablo de origen cumanagoto $(D E C H$, s. v.) y consta en la documentación escrita desde $1839^{40}$. Esta entrada posiblemente contiene uno de los primeros usos del adjetivo americano en el interior del diccionario, un adjetivo cuya historia ha estudiado Álvarez de Miranda (2002) y que, aunque aparecía ya en el DAut. en la expresión "voz americana" en dos ocasiones ${ }^{41}$, hubo que esperar la segunda edición de esta obra para constatar la adición de adjetivo americano/na en la nomenclatura académica ${ }^{42}$.

Por su parte, sabana, indigenismo de documentación antigua (DECH, s. v. y Cuervo 1901), se incorpora al diccionario con localización de su empleo (ejemplo 45).

\footnotetext{
39 Se añade también campechano (DRAE 1843), definido solo como adjetivo y no como gentilicio (DRAE 1884): “fam. Franco, dispuesto para cualquier broma y diversión”. Con este valor está atestiguado en obras de Espronceda y Bretón de los Herreros a partir de $1840(C D H)$, v. el $D E C H$ (s. v.) para la vinculación semántica entre las dos acepciones.

40 En Pichardo (1836, s. v.) aparecía con la información siguiente: "Especie de silla poltrona grande con brazos, asiento bajo y espaldar alto: comunmente las de mas lujo son de caoba forradas de marroquí ó vaqueta. En la parte occidental se dice indistintamente BUTACA ó SILLON, y algunos usan el ambiguo BUTAQUE”. Se registra la voz en varias ocasiones en la novela del cubano Cirilo Villaverde, Cecilia Valdés o la loma del ángel, publicada en $1839(C D H)$ y en obras de Mesonero Romanos y Bretón de los Herreros (1841-1843, CDH), así como en la correspondencia de Valera (847-1857, CDH). Consta el término también en algunos anuncios de la prensa española a partir de 1839 (Hemeroteca Digital). La variante butaque ya formaba parte de la nomenclatura del diccionario de Terreros (1786-1793), definida como "especie de silla poltrona en la Provincia de Caracas".

41 En el derivado desempacarse y en el indigenismo xícara; en los dos casos desaparece el adjetivo en las ediciones siguientes. Cp. para jicara, Fernández Gordillo 2006: 125-127. 42 "AMERICANO, NA. adj. El natural de América, ó lo que pertenece á ella. Americanus" (DAut. 1770). Aparte del lema americano, se halla el adjetivo en las correspondencias latinas, por ejemplo, chicha en el DAut. o pita (agave americana desde el DRAE 1817).
} 
(45) SABANA. f. Páramo, llanura, sin árboles, extensa y arenosa. Es voz de mucho uso en América (DRAE 1843).

También es posible encontrar en el aumento de 1843 algún término de flora o fauna de procedencia americana, aunque sin mencionar su origen; tal es el caso de colibrít3 y de la variante antigua alcayoba ${ }^{44}$. Se registra, además, un adjetivo relacional vinculado a un gentilicio americano - patagónico "Lo perteneciente á los patagones" ${ }^{45}$ - y la variante formal tacamacha ${ }^{46}$, equivalente al indigenismo tacamaca (DAut.). A todos ellos, se podría añadir sagú, de origen etimológico malayo $(D E C H$, s. v.) y con presencia también en América (DLE 2014), aunque la definición del DRAE 1843 no lo explicita - “Fécula que se extrae de varias especies de palmeras y se usa para sopa por ser muy nutritiva"— ${ }^{47}$.

Se descubre también alguna nueva acepción relacionada con América, así, por ejemplo, en la entrada goma se añade una quinta acepción definida como una "Especie de resina de color pardo y muy ligera que viene de América...”; en palo se agrega la estructura compleja palo brasil ó palo de brasil, una "Madera de un palo de la América meridional muy usada en las artes para teñir..."; peseta,

43 La Academia (DLE 2014) señala un origen caribe, pero el DECH lo remonta al francés. Consta también como voz indígena en Malaret 1970.

44 Conforma la nomenclatura del diccionario hasta el DRAE 1914 como variante antigua de caoba y forma parte de la decena de arcaísmos que se incorporan en esta edición del diccionario (Jiménez Ríos 2018c: 413, 2018d: 110; Freixas Alás 2019: 195). Encuentro para esta palabra solo documentación lexicográfica posterior a la novena edición del diccionario académico (por ejemplo, Diccionario histórico de la lengua española [DHLE], Fichero General) por lo que, habida cuenta del elevado número de erratas de esta edición, en su origen podría haber un simple error tipográfico, de ahí su desaparición en la primera edición del siglo xx (cp. la ficha n. ${ }^{\circ} 9$ del Fichero General, que está relacionada con la razón de su supresión).

45 Campechano/na forma parte del aumento de la novena edición, pero se define solo como adjetivo: “fam. Franco, dispuesto para cualquier broma y diversión». Más adelante (DRAE 1884), se añade otra entrada como gentilicio: «Natural de Campeche...”. v. el $D E C H$ para la posible relación etimológica entre ambos valores semánticos y Salvá 1846.

46 Se descubre, además, la desaparición de la variante tacamahaca (Fernández Gordillo 2006: 314), que se recupera en el $D R A E$ 1899, justo en el mismo lugar que ocupa en esta edición tacamacha, la cual aparece en algún texto de mediados del siglo XvIII (Fichero General).

47 Se trata, en realidad, de una reincorporación porque formó parte del $D R A E 1817$. 
aquella de la que el DAut. decía que era "voz modernamente introducida", ahora se ve acompañada por el compuesto peseta columnaria: "la labrada en América que tiene el escudo de las armas reales entre columnas, y vale cinco reales de vellon"; se incorpora también una segunda acepción a chincharrero con la descripción de "Barco pequeño que usan en Indias para pescar" (cp. Fernández Gordillo 2006: 314).

Terreno inexplorado es la posible presencia del uso americano en ciertos elementos léxicos que ingresan en el diccionario sin ningún tipo de vínculo transoceánico, pese a que la documentación textual disponible actualmente refleja un empleo mayoritario en los textos americanos. Bastará la mención del derivado costeño/ña, definido con una equivalencia sinonímica (costanero), como ocurre en el Diccionario marítimo español (1831) del que se pudo tomar la palabra. Este adjetivo, sin embargo, aparecía en las Noticias secretas del Perú de Jorge Juan y Antonio de Ulloa en 1747 (CDH) como adjetivo relacional junto al sustantivo barquillo, una combinación que se registra en otros textos, y Núñez de Taboada (1825) lo incluyó en su diccionario definiéndolo con las palabras siguientes: "Dicese de un barco pequeño que solo hace viages de puerto a puerto siguiendo la costa" ${ }^{38}$. En la Relación histórica del viaje a los reinos del Perú y Chile de Hipólito Ruiz de finales de siglo XviII (CDH), aparece la diferenciación entre "Indios Llanistas y Costeños"; el adjetivo, además, hace acto de presencia en los medios periodísticos mexicanos desde finales de siglo xviII. Por ejemplo, en la Gazeta de México de 1804 (27 de octubre) se menciona una nueva "Tienda de Caldos del Empedradillo", en la que se vende "el Vino costeño".

48 De hecho, se halla también en su diccionario bilingüe (Núñez de Taboada 1812): "CABOTIER, s. m. Barco costeño: que solo hace viages de puerto en puerto" y "COSTEÑO (BARCO), adj. Cabotier”, cuya la información se corresponde con la equivalencia que ya aparecía en el diccionario de Capmany (1805): “Cabotier. s. m. Barco costeño: que solo hace viages de puerto en puerto". 


\subsection{DRAE 1852}

Aunque no es comparable al crecimiento registrado en el $D R A E$ 1817, en el que se añadieron el doble de entradas, el aumento de la décima edición del diccionario académico (Buenafuentes de la Mata 2019) experimenta un ligero incremento con respecto a las cuatro ediciones anteriores. Es el $D R A E$ 1852, sin embargo, un tanto particular con respecto al tema estudiado por ser posterior a la publicación del Nuevo diccionario de la lengua castellana de V. Salvá, "el primero que dio cuenta de la introducción de americanismos”, en palabras de Alvar Ezquerra ([1987] 1993: 344).

Un primer examen de las adiciones apunta la existencia de abundantes coincidencias entre la nueva información de la décima edición del diccionario académico y la obra de Salvá, con lo que la enmienda de aquel podría encontrar su origen en un diccionario que tuvo como uno de sus principios rectores la apertura a la recepción del léxico trasatlántico (Seco 1987, Azorín Fernández 2008, Azorín Fernández y Baquero Mesa 2008). Efectivamente, más de cuatrocientas formas del aumento del DRAE 1852 coinciden con entradas del diccionario de Salvá, es decir, dos terceras partes del aumento corresponden a artículos que están marcados con una cruz en la obra del lexicógrafo valenciano. Estas concurrencias podrían suponer que en la enmienda de la décima edición del diccionario académico la tuvo muy presente. Si fuese así, tendría sentido preguntarse qué palabras se eligieron y si fueron voces relacionadas con América. La respuesta parece ser negativa, pues en estas coincidencias figuran muy pocas realidades relacionadas con América: los árboles y plantas cacabuete, capá y capulí, el adjetivo lépero, una legumbre (poroto) y una moneda (tlaco), además de los sustantivos cancha y pampas. A continuación (tabla 1), las voces mencionadas se muestran en paralelo (Salvá 1846 y $D R A E$ 1852) y en orden alfabético. 


\section{Tabla 1}

\begin{tabular}{|c|c|}
\hline Salvá 1846 & $D R A E 1852$ \\
\hline $\begin{array}{l}\text { + CACAHUATE y CACAHUETE. m. Planta } \\
\text { frondosa que da unas flores blancas, y cuyos vástagos } \\
\text { hincándose en la tierra producen varios bulbos de } \\
\text { la figura de un capullo de seda, aunque menores que } \\
\text { este. Cada uno contiene dos granos del grandor de un } \\
\text { garbanzo, que se comen de varios modos; pero mas de } \\
\text { ordinario tostados. Tienen el mismo nombre que la } \\
\text { planta, la cual trasladada de América á España, se ha } \\
\text { aclimatado perfectamente, sobre todo en la provincia } \\
\text { de Valencia. Se conoce con el nombre de CACAHUATE } \\
\text { en la América setentrional, con este y el de CACAHUETE } \\
\text { en España, y con el de MANí en la América medirional. }\end{array}$ & $\begin{array}{l}\text { CACAHUETE. m. Planta } \\
\text { procedente de América, que } \\
\text { se cria en varias provincias } \\
\text { meridionales de España, y } \\
\text { produce una frutilla que } \\
\text { en el gusto se parece á la } \\
\text { almendra. }\end{array}$ \\
\hline $\begin{array}{l}\text { +CANCHA. f. p. Am. M. La casa en que los vivanderos } \\
\text { venden los víveres. } \| p \text {. Am. Patio ó corral destinado á } \\
\text { algun entretenimiento ó diversión; y así se dice CANCHA } \\
\text { de bolos, de gallos, de pelota, etc. }\end{array}$ & $\begin{array}{l}\text { CANCHA. f. } \\
\text { tostadas que se } \\
\text { Perú. }\end{array}$ \\
\hline $\begin{array}{l}\text { † CAPÁ. f. Madera de un árbol del mismo nombre } \\
\text { que se cría en la isla de Cuba y Puerto Rico, la cual } \\
\text { es excelente para fondos de embarcaciones por su } \\
\text { apreciable calidad de no picarla la broma. }\end{array}$ & $\begin{array}{l}\text { CAPÁ. m. Árbol de } \\
\text { América de mucho uso en la } \\
\text { construccion de buques. }\end{array}$ \\
\hline $\begin{array}{l}\text { † CAPULI. m. Árbol mediano de América semejante } \\
\text { al cerezo, cuya fruta es sumamente delicada y tiene el } \\
\text { mismo nombre. }\end{array}$ & $\begin{array}{l}\text { CAPULÍ. m. Árbol oriundo } \\
\text { de América, que da una } \\
\text { frutilla de gusto y olor } \\
\text { agradable. || La misma fruta. }\end{array}$ \\
\hline $\begin{array}{l}\text { † LÉPERO, RA. m. y f. } p \text {. Méj. La gente de la más } \\
\text { ínfima plebe que va casi desnuda ó llena de andrajos, y } \\
\text { es infeliz por su desidia ó desarreglo. Dase alguna vez } \\
\text { este nombre al que va bien vestido para denotar que } \\
\text { carece de toda educación. }\end{array}$ & $\begin{array}{l}\text { LÉPERO. a. prov. de Méj. } \\
\text { La gente mas baja de la plebe } \\
\text { de aquella ciudad. }\end{array}$ \\
\hline $\begin{array}{l}\text { † PAMPA. m. Árbol de Filipinas cuya madera se } \\
\text { emplea para cajones y forrar los buques. } \| \text { f. p. Am. M. } \\
\text { Llanura grande. \| pl. p. Am. M. Las llanuras que hay } \\
\text { desde Buenos Aires hasta cerca de la Tierra de fuego. } \\
\| \text { PAMPAS Ó INDIOS PAMPAS. m. pl. p. Am. M. Las tribus } \\
\text { indias que viven en dichas llanuras. } \| \text { CABALLO PAMPA. } \\
\text { p. Am. M. Caballo de las llanuras de Buenos Aires. }\end{array}$ & $\begin{array}{l}\text { PAMPAS. f. pl. Llanura de } \\
\text { mucha extensión cubierta } \\
\text { de yerba, de que hay varias } \\
\text { en la América meridional, } \\
\text { donde se les da este nombre. }\end{array}$ \\
\hline $\begin{array}{l}\text { † POROTO. m. p. Am. M. Legumbre, especie de } \\
\text { alubia ó arveja. }\end{array}$ & $\begin{array}{l}\text { POROTO. m. Especie de } \\
\text { aluvia. Es voz muy usada en } \\
\text { América. }\end{array}$ \\
\hline $\begin{array}{l}\text { † TLACO. m. p. Méj. La octava parte del real de } \\
\text { América. }\end{array}$ & $\begin{array}{l}\text { TLACO. m. La octava parte } \\
\text { del real columnario. Usase } \\
\text { en América. }\end{array}$ \\
\hline
\end{tabular}


Excepto en cancha, en el que se describe una realidad distinta, existe cierta correspondencia entre ambos diccionarios, aunque hay diferencias de detalle y varía la cantidad de información. Cabría, por tanto, una indagación más extensa sobre la posible deuda de la décima edición con el diccionario de Salvá para la correcta evaluación del curso seguido en la enmienda de esta edición del diccionario.

La dependencia entre estas dos obras podría reflejarse en la incorporación del adjetivo lépero que figura con la abreviatura pr. de Méjic. de aquella obra; contrasta, sin embargo, el empleo de las marcas diatópicas del lexicógrafo valenciano con las indicaciones geográficas integradas en la propia definición y siguiendo el proceder acostumbrado de la lexicografía académica del momento en los otros ejemplos examinados.

Existe también correspondencia con la ampliación de Salvá en otras voces que se incorporaron al diccionario sin mención a América (ejemplo 46).

(46) † CACICA. f. La mujer ó hija del cacique (Salvá 1846).

CACICA. f. La mujer del cacique (DRAE 1852).

Hay que considerar, además, los cuatro gentilicios que se añaden en esta edición: chileno - como variante de chileño-, peruviano, venezolano y yucateco $^{49}$. Todos, excepto peruviano ${ }^{50}$, formaban parte del diccionario de Salvá.

En el aumento de acepciones no parece que se tuvieran en cuenta los ricos materiales americanos que atesoraba el diccionario de Salvá; esto indican las muestras comparativas realizadas tomando como base el apéndice de 1532 voces americanas identificadas en Azorín Fernández (2008). Pese a ello, se ha podido rastrear en el aumento de acepciones alguna incorporación relacionada con América: en la

\footnotetext{
49 v. Buenafuentes de la Mata 2019: 215. Yucateco figura definido como "El natural de Yucatan y lo relativo á aquel país”. Como bien aclara Fernández Gordillo (2006: 316), Yucatán fue país independiente de México en 1842, 1846-1848, pero no lo era en la fecha de edición del diccionario (Ferrer Muñoz 2002).

50 Peruviano aparece en Salvá 1846 no como gentilicio, sino en la estructura bálsamo peruviano.
} 
entrada colonial, admitida en el $D R A E$ 1837, se añade una segunda acepción con fuerte relación transatlántica: “Com. ULTRAMARINO. Así se llaman frutos COlOniales a los que proceden de América y Asia” (DRAE 1852), siguiendo seguramente el diccionario de Salvá; del mismo modo, se incorpora la combinación tifo de América (s. $v$. tifo) con la equivalencia de "La fiebre amarilla"

Además, aparecen en la enmienda de la décima edición del diccionario algunas modificaciones en las definiciones que afectan a la expresión de las coordenadas político-geográficas del término descrito, unas variaciones que reflejan los cambios políticos derivados de las independencias. Así, se han hallado ejemplos en los que se sustituye el sustantivo reino por la mención del topónimo sin esta precisión o su sustitución por país o nación (tabla 2).

\section{Tabla 2}

\begin{tabular}{|l|l|l|}
\hline \multicolumn{1}{|c|}{$D R A E 1843$} & \multicolumn{1}{|c|}{ Salvá 1846 } & \multicolumn{1}{c|}{ DRAE 1852 } \\
\hline $\begin{array}{l}\text { ARAUCANO, NA. adj. } \\
\text { El natural de Arauco, ó lo } \\
\text { perteneciente á aquel pais } \\
\text { del reino del Perú. }\end{array}$ & $\begin{array}{l}\text { ARAUCANO, NA. adj. } \\
\text { El natural de Araúco, ó lo } \\
\text { perteneciente á aquel país } \\
\text { del reino del Perú. }\end{array}$ & $\begin{array}{l}\text { ARAUCANO, NA. adj. } \\
\text { El natural de Arauco, ó } \\
\text { lo perteneciente á aquel } \\
\text { país. }\end{array}$ \\
\hline $\begin{array}{l}\text { CHAPETONADA. La } \\
\text { primera enfermedad que } \\
\text { padecen los europeos } \\
\text { después de haber llegado } \\
\text { al reino del Perú, ocasio- } \\
\text { nada de la mudanza del } \\
\text { clima. }\end{array}$ & $\begin{array}{l}\text { La primera enfermedad } \\
\text { que padecen los europeos } \\
\text { después de haber llegado } \\
\text { al reino [á la república } \\
\text { del Perú, ocasionada de la } \\
\text { mudanza del clima. }\end{array}$ & $\begin{array}{l}\text { CHAPETONADA. La } \\
\text { primera enfermedad que } \\
\text { padecen los europeos } \\
\text { después de haber llegado } \\
\text { al Perú, ocasionada de la } \\
\text { mudanza del clima. }\end{array}$ \\
\hline $\begin{array}{l}\text { CHILEÑO, ÑA. adj. El } \\
\text { natural de Chile, ó lo per- } \\
\text { teneciente á aquel reino. }\end{array}$ & $\begin{array}{l}\text { *CHILEÑO, ÑA. adm. natural de Chile, ó } \\
\text { lo perteneciente á aquel } \\
\text { reino [aquella república]. }\end{array}$ & $\begin{array}{l}\text { CHILEÑO, ÑA. adj. El } \\
\text { natural de Chile ó lo per- } \\
\text { teneciente á aquel país. }\end{array}$ \\
\hline
\end{tabular}

51 La entrada se encuentra también en Salvá (1846), aunque ninguna de las tres estructuras complejas que contiene el DRAE 1852 constan en aquel diccionario (tifo de oriente, tifo de América, tifo asiático). 


\begin{tabular}{|c|c|c|}
\hline$D R A E 1843$ & Salvá 1846 & $D R A E 1852$ \\
\hline $\begin{array}{l}\text { GUAYAQUIL. adj. que } \\
\text { se aplica á lo que es de la } \\
\text { provincia de Guayaquil } \\
\text { en el reino del Perú; y así } \\
\text { se dice: cacao GUAYAQUIL. }\end{array}$ & $\begin{array}{l}\text { GUAYAQUIL. adj. que } \\
\text { se aplica á lo que es de la } \\
\text { provincia de Guayaquil } \\
\text { en el reino del Perú; y así } \\
\text { se dice: cacao GUAYAQUIL } \\
\text { [y aun GUAYAQUIL solo } \\
\text { sustantivamente]. }\end{array}$ & $\begin{array}{l}\text { GUAYAQUIL. adj. que } \\
\text { se aplica á lo que es de la } \\
\text { provincia de Guayaquil } \\
\text { en el Perú; y así se dice: } \\
\text { cacao GUAYAQUIL. }\end{array}$ \\
\hline $\begin{array}{l}\text { PERULERO, RA. adj. El } \\
\text { natural del Perú y lo per- } \\
\text { teneciente á este reino. } \\
\text { El que ha venido desde el } \\
\text { reino del Perú á España. }\end{array}$ & $\begin{array}{l}\text { PERULERO, RA. adj. El } \\
\text { natural del Perú y lo per- } \\
\text { teneciente á este reino. ॥ } \\
\text { El que ha venido desde el } \\
\text { reino del Perú á España. }\end{array}$ & $\begin{array}{l}\text { PERULERO, RA. adj. El } \\
\text { natural del Perú y lo per- } \\
\text { teneciente á este país. } \\
\text { El que ha venido desde el } \\
\text { Perú á España. }\end{array}$ \\
\hline $\begin{array}{l}\text { QUIJO. m. Especie de } \\
\text { piedra sumamente sólida } \\
\text { y dura, en que regular- } \\
\text { mente se cria el metal en } \\
\text { las minas. Es voz usada } \\
\text { en las Indias, y princi- } \\
\text { palmente en el reino del } \\
\text { Perú. }\end{array}$ & $\begin{array}{l}\text { *QUIJO. m. Especie de } \\
\text { piedra sumamente sólida } \\
\text { y dura, en que regular- } \\
\text { mente se cria el metal en } \\
\text { las minas. Es voz usada } \\
\text { en las Indias, y princi- } \\
\text { palmente en el reino del } \\
\text { Perú [en el Perú]. }\end{array}$ & $\begin{array}{l}\text { QUIJO. m. Especie de } \\
\text { piedra sumamente sólida } \\
\text { y dura, en que regular- } \\
\text { mente se cria el metal en } \\
\text { las minas. Es voz usada } \\
\text { en las Indias, y principal- } \\
\text { mente en el Perú. }\end{array}$ \\
\hline $\begin{array}{l}\text { CHILEÑO, ÑA. adj. El } \\
\text { natural de Chile, ó lo per- } \\
\text { teneciente á aquel reino. }\end{array}$ & $\begin{array}{l}\text { * CHILENO, ÑA. adj. } \\
\text { El natural de Chile, ó } \\
\text { lo perteneciente á aquel } \\
\text { reino [aquella república]. }\end{array}$ & $\begin{array}{l}\text { CHILEÑO, ÑA. adj. El } \\
\text { natural de Chile, ó lo per- } \\
\text { teneciente á aquel país. }\end{array}$ \\
\hline $\begin{array}{l}\text { JALAPA. f. La raíz de } \\
\text { una planta que crece de } \\
\text { suyo en varias partes del } \\
\text { reino de Méjico, especial- } \\
\text { mente en la provincia de } \\
\text { Jalapa ... }\end{array}$ & $\begin{array}{l}\text { * JALAPA. f. La raíz de } \\
\text { una planta que crece de } \\
\text { suyo en varias partes del } \\
\text { reino [de la república] de } \\
\text { Méjico, especialmente en } \\
\text { la provincia de Jalapa ... }\end{array}$ & $\begin{array}{l}\text { JALAPA. f. La raíz de } \\
\text { una planta que crece de } \\
\text { suyo en varias partes de } \\
\text { Méjico, especialmente en } \\
\text { la provincia de Jalapa... }\end{array}$ \\
\hline $\begin{array}{l}\text { LACA.f. Especie de goma } \\
\text { resinosa muy encarnada } \\
\text { que elaboran sobre las } \\
\text { ramillas de un árbol de la } \\
\text { India oriental y del reino } \\
\text { de Méjico ciertos insectos, } \\
\text { y que regularmente trae } \\
\text { en granos pegados á los } \\
\text { palillos de dichas ramillas. }\end{array}$ & $\begin{array}{l}\text { LACA.f. Especie de goma } \\
\text { resinosa muy encarnada } \\
\text { que elaboran sobre las } \\
\text { ramillas de un árbol de la } \\
\text { India oriental y del reino } \\
\text { de Méjico ciertos insectos, } \\
\text { y que regularmente trae } \\
\text { en granos pegados á los } \\
\text { palillos de dichas ramillas. } \\
\text { La planta en que ese ela- } \\
\text { bora, es el }\end{array}$ & $\begin{array}{l}\text { LACA. f. Especie de goma } \\
\text { resinosa muy encarnada } \\
\text { que elaboran sobre las } \\
\text { ramillas de un árbol de } \\
\text { la India oriental y de } \\
\text { Méjico ciertos insectos, y } \\
\text { que regularmente trae en } \\
\text { granos pegados á los pali- } \\
\text { llos de dichas ramillas. }\end{array}$ \\
\hline
\end{tabular}




\begin{tabular}{|c|c|c|}
\hline$D R A E 1843$ & Salvá 1846 & $D R A E 1852$ \\
\hline $\begin{array}{l}\text { MEJICANO, NA. adj. } \\
\text { El natural de Méjico y } \\
\text { lo perteneciente á este } \\
\text { reino. Se usa tambien } \\
\text { como sustantivo. \| s. m. } \\
\text { El idioma mejicano. }\end{array}$ & $\begin{array}{l}\text { * MEJICANO, NA. adj. } \\
\text { El natural de Méjico, y } \\
\text { lo perteneciente á este } \\
\text { reino [á esta república]. } \\
\text { Se usa tambien como sus- } \\
\text { tantivo. } \| \text { - m. El idioma } \\
\text { mejicano. }\end{array}$ & $\begin{array}{l}\text { MEJICANO, NA. adj. } \\
\text { El natural de Méjico y lo } \\
\text { perteneciente á este país. } \\
\text { Se usa tambien como sus- } \\
\text { tantivo. \| s. m. El idioma } \\
\text { mejicano. }\end{array}$ \\
\hline $\begin{array}{l}\text { OCOZOAL. m. Ser- } \\
\text { piente que se halla en } \\
\text { el reino de Méjico, que } \\
\text { tiene la cabeza de víbora y } \\
\text { el vientre blanco que tira } \\
\text { algo á rojo. }\end{array}$ & $\begin{array}{l}\text { * OCOZOAL. m. Ser- } \\
\text { piente que se halla en el } \\
\text { reino de Méjico [en la } \\
\text { república mejicana], que } \\
\text { tiene la cabeza de víbora y } \\
\text { el vientre blanco que tira } \\
\text { algo á rojo. }\end{array}$ & $\begin{array}{l}\text { OCOZOAL. m. Ser- } \\
\text { piente que se halla en la } \\
\text { nacion Mejicana, que } \\
\text { tiene la cabeza de víbora y } \\
\text { el vientre blanco que tira } \\
\text { algo á rojo. }\end{array}$ \\
\hline
\end{tabular}

Puede observarse en los ejemplos anteriores que algunas de las correcciones introducidas por Salvá ya tenían el mismo sentido (entradas marcadas con un asterisco), aunque en esta obra este tipo de revisión tampoco fue exhaustiva (araucano/na, guayaquil, perulero/ra, laca). Hay, además, algunos casos de sustitución de Nueva España por Méjico (lampote, real de minas (s. v. real) y tostón 6$)^{52}$, más acorde con las denominaciones oficiales del país. Las modificaciones, sin embargo, no son metódicas y no es difícil hallar ejemplos en los que la localización se mantiene sin experimentar mudanza: por ejemplo, reino del Perú permanece en caballo aguililla (s. v. caballo), mazamorra y chapetón; reino de Chile, en oveja 2; reino de Méjico, en tacamaca.

De todos los cambios de localizaciones identificados, solo en quina la reescritura de la definición comporta la adición de “América” (ejemplos 47 y 48).

(47) QUINA ó QUINAQUINA. f. La corteza del quino antifebril, de que se conocen varias especies en el comercio con el nombre de cascarilla (DRAE 1843).

52 En estos tres ejemplos no hay ninguna corrección en Salvá (1846). Además, en tostón 6 se sustituye también “nuevo reino de Granada” por "Granada de América”. 
(48) QUINA ó QUINAQUINA. f. Corteza de varios árboles de América, de la cual se conocen diversas especies muy usadas en la medicina (DRAE 1852).

Destaca la décima edición, no tanto por la ampliación de americanismos como por los cambios en las localizaciones americanas que se ajustan a la realidad política que se había gestado tras las independencias, un pormenor de la definición que no se había enmendado con anterioridad. El cotejo realizado con la obra de Salvá lleva a concluir que es muy posible que su obra se tuviera en cuenta en muchas de ellas, aunque, por su número, hay que concluir que las voces americanas no fueron el objeto prioritario de la selección. Hay, además, alguna entrada que no muestra relación con el diccionario de Salvá (cancha, tifo) y su origen deberá buscarse en otra procedencia.

\section{Conclusión}

Como señaló Seco (1988: 85), no puede entenderse el diccionario académico sin tener en cuenta que "es un diccionario con historia" y que "es una obra en la que opera constantemente el peso de su propio pasado". En aplicación de esta idea, en este trabajo se ha intentado reconstruir “el caminar” (Alvar López 1992) del diccionario académico en la primera mitad de siglo XIX para un tipo de léxico concreto: las voces relacionadas con América.

Aparecen en este caminar las líneas evolutivas generales del diccionario. La reescritura de la definición de muchos términos vinculados a la historia natural en 1817 es reflejo de los adelantamientos científicos de la Ilustración y afianza la presencia explícita de América, tanto en la nomenclatura, con algunas incorporaciones que reflejan su magnífica biodiversidad, como en la microestructura con la mención al lugar de origen, un tipo de patrón definitorio que alcanza cierta extensión en la primera edición estudiada. Las dos ediciones siguientes, por su parte, se concentran en despojar al diccionario de ciertos materiales que se consideraron prescindibles desde distintos puntos de vista, lo que supuso una limitación 
de la ampliación y una reducción de las definiciones en las que, a menudo, se omite la indicación del origen americano. Las ediciones que se publican entre 1837 y 1852 coinciden con el surgimiento de un interés en la lexicografía no académica por la codificación lexicográfica del léxico americano, producto de una producción lexicográfica no académica orientada al mercado americano y de la cual el mejor exponente es Salvá (Seco 1987). La presencia de América en las ediciones académicas es muy limitada, pero reviste cierto interés, en especial, en la octava y décima ediciones: en la primera, el incremento halla su motor en una colaboración externa $a^{53}$; en la última, se perciben ciertos cambios cuyo origen podría encontrarse en la obra de Salvá.

Como ya se conocía, las ediciones estudiadas no entrañan una integración reseñable del vocabulario provincial al diccionario académico (Aliaga Jiménez 2000, Fernández Gordillo 2006); tampoco representan hitos importantes en la historia de la lexicografía, excepto algunas modificaciones incluidas en la quinta edición y las supresiones de las dos ediciones siguientes. La enmienda es asistemática y parcial, con lo que, en cierto sentido, el diccionario acrecienta su heterogeneidad y engendra una abigarrada convivencia entre lo viejo y lo nuevo. En su objetivo de conseguir un diccionario más manejable, las reducciones de la sexta y la séptima ediciones, en especial en la definición y en las equivalencias léxicas, implican también una pérdida de las referencias a América, piénsese en la definición del sustantivo llama, animal para el que la mención a su hábitat forma parte ineludible de su caracterización lexicográfica. También van desapareciendo, progresivamente y desde las primeras formulaciones establecidas en el DAut., las alusiones al origen de las voces (voz indiana). Con estos cambios metalexicográficos, la identificación del léxico americano, en cierto sentido, se diluye y América se agazapa en el diccionario, algo que refleja en

\footnotetext{
53 Esto recuerda las reflexiones de Morínigo (1959 y 1964) sobre los caminos por los que discurre la introducción de los americanismos en la lexicografía.
} 
cierta forma la actitud oficial del reconocimiento de la nueva realidad americana tras las emancipaciones (Rama 1982).

Efectivamente, por la propia dinámica del trabajo académico, los grandes cambios políticos que tuvieron lugar en suelo americano con las independencias no empiezan a reflejarse en el diccionario hasta 1852 y de forma muy asistemática. De hecho, excepto las modificaciones identificadas en la última edición mencionada, la gran mayoría de vocabulario relacionado con América permanece con las localizaciones políticas y administrativas coloniales hasta la segunda mitad del siglo XIX, cuando, con las ediciones de 1869 y, sobre todo, 1884, se somete el diccionario a una revisión completa y es entonces cuando cambian sustancialmente no solo la fisonomía político-administrativa de América, sino también la configuración de las entradas del diccionario.

En el terreno de las indicaciones geográficas, sin embargo, las ediciones estudiadas son testimonio de la lenta y progresiva sustitución de la denominación tradicional Las Indias por América. La primera, como reflejo de la lengua de su tiempo, era forma bien instaurada en el $D A u t .{ }^{54}$ e irá remitiendo frente a la segunda. En este sentido, la quinta edición ${ }^{55}$ presenta un importante avance en un relevo que no culminará hasta la segunda mitad del siglo XIX, cuando la undécima edición registre un mayor predominio de América, una situación que consagra la duodécima edición. La décima edición, por su parte, permite observar las primeras transformaciones derivadas de la nueva organización poscolonial. Estas pequeñas modificaciones, sin embargo, no implican una revisión de la localización americana de la voz, algo que más adelante será motivo de crítica por parte de Cuervo ([1874] 1948: 124, v. Seco 1988: 92). Relacionados con la expresión de la localización y con la formación de las nuevas naciones americanas se encuentran los gentilicios que se empiezan a documentar en el aumento de 1852 y que

\footnotetext{
54 América solo aparece en 20 ocasiones en el DAut., frente a 279 apariciones de Indias (Fernández Gordillo 2006: 123-126).

55 En el DRAE 1817, se han podido identificar 93 casos de Las Indias frente a 72 de América.
} 
también son reflejo de las transformaciones políticas de la primera mitad de siglo XIX (Fernández Sebastián 2009: 56).

Cabe advertir que las ediciones del periodo estudiado, salvo en algún caso aislado, insertan las referencias a América en la propia definición, un sistema presente en el diccionario desde la primera edición del $D A u t$. y que no cambiará ni en su segunda edición (1770) ni en el DRAE 1780. Este tipo de configuración se mantendrá en lo fundamental hasta la undécima edición del diccionario (DRAE 1869) y no se normalizará adoptando el sistema de acotaciones en abreviatura a semejanza de otras precisiones de carácter diatópico hasta la duodécima edición ( $D R A E$ 1884), momento en el que la Academia, como reflejo de la propia evolución políticosocial, empezará a reflejar el interés por América en el devenir del diccionario, en un siglo en el que la presencia de los americanismos "sufrió un cambio considerable" (Alvar Ezquerra 1996-1997: 82).

Finalmente, cabe advertir que quizá la presencia de América late en otro componente léxico presente en la obra académica del periodo considerado, muy probablemente, sin que los académicos decimonónicos fueran conscientes de ello. Al estudiar el nacimiento y evolución del adjetivo americano, Álvarez de Miranda (2002: 85) llega a la conclusión de que "el nuevo gentilicio «nació» en América y que - pronto repartido entre la mera referencia geográfica y la designación de los nacidos en ella- su adopción ha de relacionarse con la maduración de la conciencia y el orgullo criollos”. El ejemplo de americano puede iluminar la interpretación de algunos derivados que, por su propia condición lexicológica, fueron incorporados a los diccionarios académicos con definiciones muy poco específicas y que un análisis histórico-documental, tal como advirtió acertadamente García Godoy (2015: 112, 117-119), permitiría trazar algún vínculo con el habla americana, ya en su gestación, ya en su uso. Ilustración de ello podría ser el adjetivo costeño/ña, al que se ha hecho referencia anteriormente ( $\mathbb{S} 2.3$.). Se podría también estudiar si existe esta trabazón en algunos derivados deverbales con los sufijos vocálicos $-e$ y $-o$ incorporados en el diccionario a lo largo del periodo estudiado (Clavería Nadal 
2018), como desarrollo (DRAE 1817), deterioro (DRAE 1817), retardo (DRAE 1822), desemboque (DRAE 1832, $\$ 2.3$.). Son voces que presentan documentación americana muy temprana (BoydBowman 2015, CDH, CORDIAM ${ }^{56}$ ), aunque, indudablemente, hasta que los corpus no atesoren mayor cantidad de datos, resultará imposible realizar mayores precisiones para la gestación e historia de unos vocablos que los diccionarios acogen con una información lexicográfica mínima.

\section{Referencias bibliográficas}

Actas $=$ Real Academia EsPañola (1829-1840)

Actas, Libro 21, desde 8 de enero de 1829 hasta 15 de octubre de 1840 [Archivo de la Real Academia Española].

Aliaga Jiménez, José Luis

2000 Aspectos de lexicografía española. El léxico aragonés en las ediciones del diccionario académico. Zaragoza: Institución Fernando el Católico.

Alvar EzQuerra, Manuel

[1986] 1993 "Los regionalismos en los diccionarios y vocabularios regionales”. En Lenguas peninsulares y proyección hispánica. Coord., Manuel Alvar. Madrid: Fundación Friedrich EbertInstituto de Cooperación Iberoamericana, 175-197. [Citado por Lexicografía descriptiva. Barcelona: Biblograf, 1993, 313331].

Alvar Ezquerra, Manuel

[1987] 1993 "La recepción de americanismos en los diccionarios generales de la lengua”. En I Congreso Internacional sobre el Español de América (San Juan de Puerto Rico, octubre de 1982). San Juan, 209-218. [Citado por Lexicografía descriptiva. Barcelona: Biblograf, 1993, 343-351].

Alvar EzQuerra, Manuel

1996-1997 “Lexicografía dialectal”. ELUA. 11, 79-108. <HTTPS://DOI. ORG/10.14198/ELUA1996-1997.11.03>

56 Corpus Diacrónico y Diatópico del Español de América 
Alvar López, Manuel

1992

"El caminar del diccionario académico". En Actas del IV Congreso Internacional de EURALEX'90 Proceedings. Barcelona: Biblograf, 3-27.

Álvarez de Miranda, Pedro

2002 "Para la historia de americano". En Pulchre, bene, recte. Estudios en homenaje al prof. Fernando González Ollé. Eds., Carmen Saralegui y Manuel Casado. Navarra: Eunsa, 73-87.

Álvarez de Miranda, Pedro [2010] 2016 “Café”. En Más que palabras. Barcelona: Galaxia Gutenberg. AZORÍn FERnÁndeZ, Dolores

2008 "Para la historia de los americanismos en los diccionarios del español”. Revista de Investigación Lingüística. 11, 13-43.

Azorín Fernández, Dolores y Rosario Baquero Mesa

2008 "Los americanismos en el Nuevo diccionario de la lengua castellana de Vicente Salvá”. En Actas del II Congreso Internacional de Historia de la Lengua Española. Eds., Manuel Ariza, Rafael Cano, Josefa Mendoza, Antonio Narbona. Madrid: Arco/Libros, II, 963-970.

BOHÓRQUEZ, Jesús Gútemberg

1984 Concepto de 'americanismo' en la historia del español. Bogotá: Instituto Caro y Cuervo.

Boyd-Bowman, Peter

2015 Léxico bispanoamericano (1493-1993). Consultado: 15 de septiembre de 2020. <https://textred.spanport.lss.wisc.edu>

Buenafuentes De La Mata, Cristina

2019 "La décima edición del Diccionario de la lengua castellana de la Real Academia Española (1852): el aumento y la supresión de voces”. ELUA. Anexo 5, 205-229.

Cala Carvajal, Rafael

2001-2002 "La coherencia en lexicografía. El caso de algunos indoamericanismos en el Diccionario de Autoridades (1726-1739)". Revista de Lexicografía. 8, 7-24. <https://doi.org/10.17979/ rlex.2002.8.0.5584> 
CARriet Valiente, Erica

2017 "La séptima edición del diccionario académico (DRAE 1832)". Revista de Lexicografía. 23, 39-65. <https://doi.org/10.17979/ rlex.2017.23.0.4695>

$C D H=$ INSTITUTO DE INVESTIGACiÓN RAFAel LAPESA DE LA REAL ACADEMIA ESPAÑOLA

Corpus del Nuevo diccionario histórico (CDH). Consultado: 15 de septiembre de 2020. <http://web.frl.es/CNDHE>

Clavería Nadal, Gloria

2016 De vacunar a presupuestar: la lexicografía académica decimonónica y el neologismo. Madrid/Frankfurt: Iberoamericana/ Vervuert.

Clavería Nadal, Gloria

2018 "Notas sobre la historia de los derivados con sufijos $-a,-e$, - $o$ en español moderno (siglos XVIII y XIX) a la luz de la documentación lexicográfica”. Estudios de Lingüística del Español (ELiES). 39, 181-203.

Clavería Nadal, Gloria

2019 "El diccionario de la Academia y su tiempo: DRAE 1817DRAE 1852”. ELUA. Anexo 5, 13-45.

Clavería Nadal, Gloria

2020 "El Diccionario de la lengua castellana (1817-1832) y la propuesta decimonónica de diccionario manual”. Boletín de la Real Academia Española. 100, cuaderno 321, 15-52.

Clavería Nadal, Gloria

en prensa "América en el Diccionario de la lengua castellana de la Real Academia Española, (DRAE 1817)”. En Actas del XI Congreso Internacional de Historia de la Lengua Española. Lima.

Clavería Nadal, Gloria, y Margarita FreiXas Alás (coords.) 2018 El diccionario de la Academia en el siglo XIX: la quinta edición (1817) al microscopio. Madrid: Arco/Libros.

Clavería Nadal, Gloria y Ana Paz Afonso

2018 "El discurso científico en la definición lexicográfica académica (DRAE 1817-1852)”. En Nuevas perspectivas en la diacronía de las lenguas de especialidad. Eds., Xosé Afonso Álvarez, 
Jairo Javier García, Manuel Martí y Ana María Ruiz. Alcalá de Henares: Universidad de Alcalá, 69-85.

Company Company, Concepción

2019 "La voz indio en la documentación americana de 1494 a 1905. Un acercamiento gramatical a la historia conceptual”. Lexis. 43, 1, 5-54. <https://doi.org/10.18800/lexis.201901.001>

Congosto, Yolanda y Miguel Ángel Quesada

2009 "Los americanismos en los diccionarios académicos (17262001). La aportación de Humberto López Morales”. En Estudios de lengua española; descripción, variación y uso. Homenaje a Humberto López Morales. Coords., Victoria Camacho-Taboada, José Javier Rodríguez Toro y Juana Santana Marrero. Madrid/Frankfurt: Iberoamericana/Vervuert, 191-236.

Corbella, Dolores

2016 "La selección de canarismos del DRAE". Revue de linguistique romane. $80,317-218,101-160$.

CORDIAM = ACADEMIA MEXICANA DE LA LENGUA

s/a Corpus Diacrónico y Diatópico del Español de América. Consultado: 15 de septiembre de 2020. <www.cordiam.org>

Cuervo, Rufino José

[1874] 1948 "Observaciones sobre el Diccionario de la Real Academia Española (Undécima edición, año de 1869)”. Anuario de la Academia Colombiana. 1. [Reproducido en Disquisiciones sobre Filología Castellana. Buenos Aires: Librería y Editorial «El Ateneo», 1948, 119-145].

Cuervo, Rufino José

1901 “Sabana”. Romania. XXX, 123-127.

De Beni, Matteo

2014) "Indoamericanismos léxicos del ámbito de la zoología en los diccionarios españoles”. En Fronteras y diálogos. El español y otras lenguas. Ed., José M. ${ }^{a}$ Santos Rovira. Lugo: Axac, 101-116.

DECH = Corominas, Joan y José Antonio Pascual

1980-1991 Diccionario crítico etimológico castellano e hispánico. Madrid: Gredos. Versión en CD-ROM (2012). 
DHLE $=$ REAL ACADEMIA ESPAÑOLA

1960-1996 Diccionario bistórico de la lengua española, (a-apasanca, b-bajoca). Madrid: Seminario de Lexicografía.

Diccionario marítimo español

1831 Madrid: Imprenta Real.

DLE 2014 = Real Academia EsPañola

s/a Diccionario de la lengua española. 23. ${ }^{a}$ ed. Consultado: 15 de septiembre de 2020. <https://dle.rae.es>

FERNÁNDEZ GoRdILLO, Luz

2005-2006 "Los americanismos en el Diccionario de Autoridades. Tratamiento y repercusiones de algunos de éstos en la trayectoria de las distintas ediciones del DRAE". Revista de Lexicografía. 12, 121-158. <https://doi.org/10.17979/rlex.2006.12.0.4769>

FERNÁNDEZ GORDILLO, Luz

2006 Tratamiento lexicográfico de los mexicanismos y seudomexicanismos en los diccionarios académicos. Tesis doctoral. México: El Colegio de México.

Fernández Sebastián, Javier (director)

2009 Diccionario político y social del mundo iberoamericano. La era de las revoluciones, 1750-1850. Madrid: Fundación CarolinaSociedad Estatal de Conmemoraciones Culturales-Centro de Estudios Políticos y Constitucionales.

FERrer MuÑoz, Manuel

2002 "Un cuarto de siglo de constitucionalismo en Yucatán (18251850)". Anuario Mexicano de Historia del Derecho. 14, 101-127.

Fichero General = ReAL ACADEMIA EsPaÑola

Fichero General de la Lengua Española. Consultado: 15 de septiembre de 2020. <http://web.frl.es/fichero.html>

Forgas Berdet, Esther y María Herrera Rodrigo

2002 "Análisis del texto lexicográfico: lenguaje científico versus subjetividad”. Tonos. Revista electrónica de estudios filológicos. 4, noviembre 2002, sin paginación. 
Freixas Alás, Margarita

2019 "La lexicografía académica de mediados del siglo XIX: EL AUMENTO DE VOCES EN LA NOVENA EDICIÓN DEL DRAE (1843)”. ELUA. Anexo 5, 181-203.

García de la Concha, Víctor

2014 La Real Academia Española. Vida e historia. Madrid: EspasaCalpe.

García Godoy, M. ${ }^{a}$ Teresa

1998 Las cortes de Cádiz y América. El primer vocabulario liberal español y mejicano. Sevilla: Diputación de Sevilla.

García Godoy, M. ${ }^{a}$ Teresa

2015 "La lengua de las primeras constituciones hispánicas: el cambio léxicosemántico”. En Actas del IX Congreso Internacional de Historia de la Lengua Española. Tomo I. Ed., José M. ${ }^{a}$ García Martín. Madrid-Frankfurt: Iberoamericana-Vervuert, 107-132.

GÓmEZ de EnTERríA, Josefa

2018 "Las voces de ciencias naturales y áreas afines”. En El diccionario de la Academia en el siglo XIX: la quinta edición (1817) al microscopio. Coords., Gloria Clavería Nadal y Margarita Freixas Alás. Madrid: Arco/Libros, 275-311.

Hemeroteca Digital = Biblioteca Nacional de España s/a Hemeroteca Digital. Consultado: 15 de septiembre de 2020. <http:// hemerotecadigital.bne.es>

JimÉNEZ Ríos, Enrique

2018a "Cambio de orientación en la lexicografía de la Real Academia Española a propósito de los arcaísmos en el DRAE de 1822”. Orillas, Rivista d'Ispanistica. 7, 309-328.

JimÉNEZ Ríos, Enrique

2018b "El diccionario, fuente para la historia del léxico: la supresión de arcaísmos gráficos en la sexta edición del Diccionario de la lengua castellana de la Real Academia Española (1822)". Boletín de Filología de la Universidad de Chile (BFUCh). LIII/1, 131-168.

JimÉNEZ Ríos, Enrique

2018c "La revisión de arcaísmos en el DRAE en la primera mitad del siglo XIX”. Estudios humanísticos. Filología. 40, 407-431. 
JimÉnEz Ríos, Enrique

2018d “Tipología de arcaísmos en el DRAE en la primera mitad del siglo XIX". Anuario de Estudios Filológicos. 41, 95-113. $<$ https://doi.org/10.17398/2660-7301.41.95>

JiméNEZ Ríos, Enrique

2019 "Participio pasivo y arcaísmo en el DRAE (ediciones de 1822 y 1832)”. ELUA. Anexo 5, 233-251.

Julià Luna, Carolina

2019 "Voces y acepciones nuevas en el DRAE 1837". ELUA. Anexo $5,143-180$.

Lemateca del DRAE [en línea]. <www.lemateca.detede.cat>

López Morales, Humberto

1971 "Contribución a la historia de la lexicografía en Cuba: observaciones prepichardianas". Estudios sobre el español de Cuba. Madrid: Las Américas, 88-106.

LujÁn, Marta

2017 "El español de América a la luz del dialogismo de contacto". En Textos, imágenes y símbolos: lengua y cultura en la América virreinal. En homenaje a Claudia Parodi. Ed., Ángela Helmer. Madrid/Frankfurt: Iberoamericana-Vervuert, 291-315.

LujÁn, Marta

en prensa "El nombre de América”. En Actas del XI Congreso Internacional de Historia de la Lengua Española. Lima.

Malaret, Augusto

1947 "Los americanismos en el Diccionario de Autoridades". Revista Universidad Católica Bolivariana. 13, n. ${ }^{\circ}$ 50, 150-167.

Malaret, Augusto

1967 "Nuestra historia natural y el Diccionario Académico". Revista del Instituto de Cultura Puertorriqueña. 35, 10-13.

Malaret, Augusto

1970 Lexicón de fauna y flora. Madrid: Comisión Permanente de Asociación de Academias de la Lengua Española.

Morínigo, Marcos A.

1959 "La formación léxica regional hispanoamericana”. En Programa de Filología Hispánica. Buenos Aires: Editorial Nova, 56-70. 
Morínigo, Marcos A.

1964 "La penetración de los indigenismos americanos en el español”. En Presente y futuro de la lengua española. Volumen II. Madrid: Ediciones Cultura Hispánica, 217-223.

Muñoz Armijo, Laura

2018 "La sinonimia y las remisiones". En El diccionario de la Academia en el siglo XIX: la quinta edición (1817) al microscopio. Coords., Gloria Clavería Nadal y Margarita Freixas Alás. Madrid: Arco/Libros, 203-221.

NTLLE $=$ REAL ACADEMIA EsPAÑOLA

2001 Nuevo Tesoro Lexicográfico de la Lengua Española. Madrid: Espasa, edición en DVD. También disponible en $<$ http://ntlle. rae.es $>$.

Pichardo, Esteban

1836 Diccionario provincial de voces cubanas. Matanzas: Imprenta de la Real Marina.

Rama, Carlos

1982 Historia de las relaciones culturales entre España y América Latina. Siglo XIX. México-Madrid-Buenos Aires: Fondo de Cultura Económica.

Real Academia Española

1838 Reglas para la corrección y aumento del diccionario. Madrid: Imprenta Nacional.

Roca de Togores, Mariano

[1861] 1870 “Reseña histórica de la Academia Española”. En Memorias de la Academia Española. Madrid: Imprenta y esterotipia de M. Rivadeneyra, I, 7-128.

Rodríguez BARcia, Susana

2008 La realidad relativa. Evolución ideológica en el trabajo lexicográfico de la Real Academia Española (1726-2006). Vigo: Universidade de Vigo.

Rodríguez Ortiz, Francisco y Cecilio Garriga Escribano

2010 "La teoría lexicográfica de la Academia en los siglos XVIII y XIX a través de las Reglas". Quaderns de Filologia. Estudis lingüístics. 15, 31-56. 
Romero Gualda, M. ${ }^{a}$ Victoria

1992 "Indigenismos en dos diccionarios españoles: Autoridades y Terreros”. En Las Indias (América) en la literatura del Siglo de Oro: homenaje a Jesús Cañedo. Ed., Ignacio Arellano. Kassel: Reichenberger, 265-283.

SAlvador Rosa, Aurora

1985 "Las localizaciones geográficas en el Diccionario de Autoridades”. Lingüística Española Actual. 7, 103-139.

SeCo, Manuel

1987 "El nacimiento de la lexicografía moderna no académica”. En Estudios de lexicografía española. Madrid: Paraninfo, 129-151.

SeCo, Manuel

1988 "El léxico hispanoamericano en los diccionarios de la Academia Española”. Boletín de la Real Academia Española. 68, 85-98.

Soux, M. ${ }^{a}$ Luisa

2016 “Apuntes para una historia del café en los yungas paceños". Historia. 37, 43-74.

Terrón Vinagre, Natalia

2019 "Historia de la lengua y lexicografía: el aumento de voces en la $6 .^{a}$ edición del Diccionario de la Academia (1822)”. En Actas del X Congreso Internacional de Historia de la Lengua Española. Volumen II. Eds., M. ${ }^{a}$ Luisa Arnal Purroy, Rosa M. ${ }^{a}$ Castañer Martín, José M. ${ }^{a}$ Enguita Utrilla, Vicente Lagüéns Gracia y M. ${ }^{a}$ Antonia Martín Zorraquino. Zaragoza: Institución Fernando el Católico, 1325-1341.

Terrón Vinagre, Natalia y Joan Torruella Casañas

2019a "La definición sinonímica en la sexta edición del Diccionario de la lengua castellana de la Real Academia Española". Revista de Filología de la Universidad de la Laguna. 39, 307-328.

Terrón Vinagre, Natalia y Joan Torruella Casañas

2019b "Estudio de la sexta edición del Diccionario de la lengua castellana de la Real Academia Española”. ELUA. Anexo $5,109-142$. 
WERNER, Reinhold

1983 "Die Amerikanismen im Diccionario de Autoridades". En Iberoamérica. Historia-sociedad-Literatura. Homenaje a Gustav Siebenmann. Eds., José Manuel López Abiada y Titus Heydenreich. Munich: Wilhem Fink, 1075-1082.

WERNER, Reinhold

1984 "Die Amerikanismen im Handwörterbuch der Real Academia Española”. En Spanien und Lateinamerika. Beiträge zu Sprache, Literatur, Kultur. Homenaje a Anton Bemmerlein. Eds., José M. Navarro y Carlos Segoviano. Nürnberg: Deutscher Spanischlehrer-Verband, 530-551.

WERNER, Reinhold

1994 "El diccionario de Esteban Pichardo". En Lengua y cultura en el Caribe hispánico. Eds., Jens Lüdtke y Matthias Perl. Tübingen: Max Niemeyer, 109-129.

Zamora MunNé, Juan C.

2001 "Contribuciones a la lexicografía cubana del siglo XIX". Historiographia Lingüistica. XXVIII, 1/2, 85-100.

Zamora Vicente, Alonso

1999 Historia de la Real Academia Española. Madrid: Espasa.

Recepción: 13/10/2020

Aceptación: 15/02/2021 